\title{
Composer l'identité nationale : la musique grecque au miroir de la littérature musicologique
}

Composing National Identity: Greek Music in the Mirror of Musicological Literature

\section{Georges Kokkonis}

\section{OpenEdition}

Journals

Édition électronique

URL : http://journals.openedition.org/etudesbalkaniques/258

ISSN : 2102-5525

Éditeur

Association Pierre Belon

Édition imprimée

Date de publication : 1 janvier 2006

Pagination : $59-104$

ISBN : 978-2-910-86006-6

ISSN : $1260-2116$

Référence électronique

Georges Kokkonis, "Composer l'identité nationale : la musique grecque au miroir de la littérature musicologique », Études balkaniques [En ligne], 13 | 2006, mis en ligne le 01 septembre 2009, consulté le 03 mai 2019. URL : http://journals.openedition.org/etudesbalkaniques/258

Ce document a été généré automatiquement le 3 mai 2019.

Tous droits réservés 


\section{Composer l'identité nationale : la musique grecque au miroir de la littérature musicologique}

Composing National Identity: Greek Music in the Mirror of Musicological

Literature

Georges Kokkonis

\section{Introduction}

1 À l'ère de la formation des nationalités, au XIX siècle, il est difficile de considérer quelque phénomène culturel qui soit sans toucher à la question identitaire. Cette question est en effet d'une envergure universelle; elle se retrouve dans les moindres recoins de l'édifice des valeurs qui se conjuguent pour donner forme aux différents aspects des réalités du moment, politiques, sociales, économiques, artistiques, etc. Elle évolue avec l'évolution de ces dernières, elle leur doit ses accents plus ou moins aigus ; c'est d'elles qu'elle tire sa raison première, avant d'en arriver carrément à les transcender.

2 La musique néohellénique est un de ces topoi de la géographie culturelle qui se trouvent par définition engagés dans l'argumentation identitaire ; les conditions historiques, dans lesquelles émerge la Grèce moderne, lui dictent une physionomie originale, révélant dans son relief les multiples enjeux qui conditionnent la culture néohellénique. Ce que nous chercherons à mettre au jour dans les pages qui suivent.

Quand on parle en Grèce de "musique néohellénique », on entend exclusivement la création musicale «savante». Cette sémantique date de l'apparition des premiers manuels d'histoire de la musique ${ }^{1}$, pour s'imposer depuis dans les usages, articles musicologiques, articles de dictionnaires ${ }^{2}$, critique musicale, et rester en vigueur jusqu'à nos jours. L'adjectif « néohellénique » désigne un trait identitaire important : il renvoie à la création du nouvel État grec, tel qu'il est issu de la guerre d'Indépendance contre 
l'Empire Ottoman (1821-1829) et à la nouvelle culture que cette ère introduisit pour les habitants de l'espace hellénique.

4 L'attribut le plus caractéristique de cette culture, c'est qu'elle se veut issue d'une lignée historique ininterrompue, ralliant son présent aux civilisations de l'Antiquité et de Byzance. Le principe de la " continuité historique » anime en effet pendant cette période tous les esprits dans les domaines de l'Histoire et de l'Histoire littéraire ${ }^{3}$.

5 En ce qui concerne la création musicale savante, l'appropriation exclusive de l'adjectif «néohellénique » va de pair avec une attitude hégémonique, qui exclut tout autre style musical fleurissant au cours du XIX $\mathrm{X}^{\mathrm{e}}$ siècle en Grèce, que ce soit la musique légère, populaire urbaine ou populaire rurale, etc., et même les traditions savantes de la périphérie géographique et/ou culturelle (musiques savantes de l'Orient, musiques de l'Heptanèse ionienne italianisante...). Contrairement à la production "officielle», la grécité de ces dernières est à prouver, donc leur style est à " corriger ». À l'issue de cette homologation "nationale », l'indifférence et le mépris sont réservés au chapitre de la création musicale (orale ou écrite) qui ne peuvent pas en être récupérés. L'attribut sine qua non de l'esthétique musicale est la grécité ; la présence ou l'absence de cet attribut, sa qualité et ses sources d'inspiration animent tous les débats et génèrent toutes les tendances stylistiques.

6 Le statut hégémonique de la musique savante ressort d'un vaste réseau d'interférences entre les acteurs et les idées animant les grands débats autour de l'identité nationale. Issus des classes sociales dirigeantes, ces derniers se développent tout au long du XIX ${ }^{e}$ siècle et jusqu'à l'entre-deux-guerres, et illustrent de manière significative le processus et les stratégies politiques de l'européanisation du pays. Ils offrent de ce fait un terrain propice pour le chercheur qui aspire à comprendre le tissage culturel qui s'opère pendant cette période, enveloppant dans les fondements de la culture néohellénique des usages et surtout des mœurs que chacun peut signaler dans la synchronie grecque actuelle. Nous allons donc emprunter ce chemin pour rendre compte des enjeux qui sous-tendent les débats essentiels autour de la constitution d'un art musical nouveau, qui se veut savant et surtout national.

7 Avant de commencer notre périple, il est important de signaler l'absence en Grèce d'une tradition musicale savante, hormis celle qui était liée à la pratique ecclésiastique, communément désignée par l'expression «musique byzantine». Cette tradition comporte également des formes séculières, qui sont toutefois trop proches de la musique de la cour ottomane pour être appréciées sans préjugé ethnique au lendemain de la Révolution. D'importants compositeurs grecs, comme Zacharias, Pétros Lambadarios, Nikolakis, Antonis et Yannis Kyriazidis et bien d'autres, ont néanmoins légué des œuvres importantes de ce style, qui reste malheureusement inconnu du grand public ${ }^{4}$. Cette lacune conduisit inévitablement la culture néohellénique à l'adoption ad hoc de la musique occidentale, devenue dès lors le véhicule de l'expression musicale officielle, voire institutionnelle. Ceci est évidemment chose attendue, qui n'a pas besoin d'être soulignée particulièrement; mais elle entraine une conséquence qui n'a pas souvent attiré l'intérêt des chercheurs, bien qu'elle soit d'une importance majeure pour la sociologie de l'art néohellénique. La musique occidentale, plus qu'un épiphénomène de style, est en Grèce moderne le symbole principal de la culture de l'élite lettrée. Or cette musique contribue, au-delà de ses fonctions sociales, à une cause nationale qui exige l'unanimité du sentiment collectif dans la nouvelle identité culturelle. Elle fait alors partie intégrante de la représentation sociale du nouvel État-Nation, dont la formation et 
l'évolution relèvent de la continuité historique ralliant dans son schème identitaire le passé, qu'il soit proche ou lointain, mais en même temps l'affirmation de son destin européen.

Durant le XIXe siècle, il n'est pas de domaine intellectuel en Grèce qui ne soit imprégné par les courants romantiques européens. Ces courants montrent très tôt le chemin aux littéraires pour se tourner vers les traditions populaires orales : elles assurent en effet un fonds culturel commun capable d'illustrer les particularités nationales et revendiquer de ce fait une autonomie esthétique vis-à-vis de la création musicale européenne. Les élites dirigeantes adoptèrent très tôt le choix de se représenter à travers un art savant qui pourrait satisfaire la demande identitaire de l'incorporation du passé historique dans les créations du présent.

9 Pendant le $\mathrm{XX}^{\mathrm{e}}$ siècle, la culture néohellénique, engagée dans de nouveaux chemins et affrontant de nouveaux enjeux, continue à invoquer le passé ; la question identitaire conditionne toujours le contexte historique, tout en restant conditionnée à son tour par lui, notamment dans son osmose avec la modernité. La littérature et les arts plastiques y trouvent une issue créative; la musique par contre, reste fortement dépendante de la tutelle d'un nombre de personnalités et d'un réseau d'institutions solidement agrippés à des stéréotypes anachroniques.

10 À l'heure actuelle, la recherche musicologique n'a pas encore suffisamment éclairé le champ de la musique néohellénique. Tracer le cheminement esthétique de cette dernière n'est pas possible sans la publication et l'enregistrement des œuvres, qui restent en grande partie inconnues. Afin de combler cette lacune et de pouvoir mettre au jour la scène musicale néohellénique dans son milieu historique, nous nous sommes tourné vers la littérature musicale, à savoir les textes qui traitent du sujet, essais, analyses, critiques, manifestes ou simplement des chroniques journalistiques. Cette littérature présente un intérêt particulier dans la mesure où elle reflète les différentes tendances esthétiques et/ ou idéologiques, en offrant en même temps une certaine image de leur réception et de leur perception.

\section{La littérature musicale grecque}

\section{A. Le XIX ${ }^{\mathrm{e}}$ siècle : après la guerre d'Indépendance, une nouvelle ère musicale}

11 Les comptes rendus des premiers concerts donnés en Grèce après la libération de l'occupation ottomane sont les premières traces d'une activité «musicologique», qui revêt à ce propos une simple forme descriptive, mais très révélatrice du champ socioculturel de l'époque où la culture musicale cherche à se faire une place.

Si la tradition musicale populaire connait un essor important au moment de la guerre d'Indépendance grecque, notamment avec la multiplication des chansons louant les exploits des héros révolutionnaires, la tradition savante occidentale reste complètement inconnue, à la seule exception des îles ioniennes, qui se trouvent sous occupation francovénitienne, et des nombreuses communautés de la diaspora, dispersées sur tout le continent européen.

13 Les premiers concerts de musique dite "classique » ont lieu autour de 1834, tout de suite après la constitution du jeune État grec. Le roi Othon, d'origine bavaroise, fait venir à 
Athènes des orchestres philharmoniques militaires, constitués et dirigés par des Bavarois. D'autre part, des troupes italiennes introduisent pour le public athénien l'opéra italien. En 1834 on importe les premiers pianos, cherchant spontanément à organiser une éducation musicale de niveau supérieur.

Durant les années 1840 , les représentations d'opéra italien se multiplient, suscitant aussi les premières critiques journalistiques, de caractère plutôt naïf ${ }^{5}$. La formation des rédacteurs, pour la plupart ignorants de la musique ou de l'esthétique, ne leur permet pas de commentaires allant plus loin que la portée sociale de l'événement, ce qu'ils compensent en exagérant l'exaltation de la carrière des chanteuses italiennes. Il n'est pas rare d'ailleurs que l'auteur de la critique se trouve absent de la salle du spectacle, se fiant en toute crédulité aux informations recueillies ultérieurement auprès du public ${ }^{6}$.

Cette entrée en scène de la musique savante occidentale, par le biais de l'entourage royal, visiblement étranger aux mœurs locales, et son adoption audacieuse par une classe sociale fortement contestée par un public encore non initié au mode de vie occidental, cette entrée donc ne peut que marquer fortement toute la vie musicale en Grèce. Désormais la distinction entre ce qui est " grec » et ce qui est « importé » ne cesse d'être au cœur de tous les débats. Et cette polémique, qui est souvent fort intéressante comme elle peut facilement tourner à la dérision, sous-tend toute évolution de la pensée musicale et de la musicologie ; il ne serait pas exagéré de dire que son écho se fait toujours sentir aujourd'hui...

es lacunes institutionnelles en ce qui concerne l'éducation musicale, ainsi que la production limitée de spectacles musicaux et de concerts vont de pair avec l'absence d'une littérature musicale systématique. Tout au long du XIX $\mathrm{X}^{\mathrm{e}}$ siècle, la seule source d'informations sur la vie musicale d'Athènes est la presse quotidienne, qui relate des rapports de concerts et d'autres manifestations culturelles. Les auteurs éponymes ou anonymes de ces notices, bien brèves pour la plupart, sont très souvent des journalistes non spécialisés, qui se limitent à des textes descriptifs pleins d'images pittoresques; aucune réflexion ne s'y infiltre quant à l'essence de la question.

17 La critique musicale, qui fut longtemps l'affaire de ces journalistes, devient beaucoup plus intéressante quand les intellectuels de l'époque décident d'en faire leur terrain. Provenant de champs divers, souvent étrangers à la musique même, comme celui de la peinture ou de la littérature, ils articulent une opinion qui a un impact considérable et influence de façon décisive les artistes aussi bien que le public. Dans leurs textes, ils dessinent une image réaliste de la vie musicale athénienne, foisonnant d'informations précieuses sur ses acteurs. D’après leur témoignage, la primauté du théâtre musical (mélodrame ${ }^{7}$ et opéra) donné par des troupes théâtrales en provenance d'Italie est incontestable à cette époque. Il s'agit d'un goût commun à tous les peuples balkaniques sortant de l'occupation ottomane, qui va de pair avec la diffusion prolifique de la production musicale italienne; la répugnance envers le mélodrame italien est à cette époque entretenue surtout par les forces sociales qui aspiraient à se servir du théâtre comme agent de l'éveil national dans tous les Balkans ${ }^{8}$.

Selon l'historien de l'art Kostas Baroutas, toutes les sources de cette époque montrent que les Athéniens sont sous l'emprise d'un " amok mélodramatique "9. Nombreux sont ceux qui, curieux et enthousiastes, se ruent dans les salles, qui deviennent le théâtre de toutes sortes de scènes pittoresques : "D'habitude, les spectateurs se partageaient en deux camps, dont le premier supportait une soprano et le second une autre. Lorsque les premiers applaudissaient, ou lorsqu'ils offraient des produits agricoles (pigeons, poules, 
oies, et même des petits cochons parés, bouteilles de vin, paniers pleins d'œufs et bouquets de fleurs fraîches), ceux du camp opposé désapprouvaient, en sifflant comme des démons et en jetant sur la scène des légumes et des pièces de monnaie $\aleph^{10}$. Edmond About, qui visite Athènes en 1854, témoigne aussi de ces gestes de culte des cantatrices : "Souvent la galanterie ingénieuse des dilettanti jette aux actrices des bouquets de pigeons vivants, liés à grand renfort de faveurs roses. Pendant ce temps, d'autres amis, placés au paradis, sèment dans la salle des papiers blancs, verts et roses, imprimés en lettres de toutes couleurs, et même, si je ne me trompe, en lettres d'or. Ce sont des vers grecs, italiens ou français, à la louange de l'artiste $»^{11}$. Ce transfert de l'intérêt du public de l'œuvre à la personne de l'artiste, ou plutôt aux charmes féminins des protagonistes italiennes, déclenche une foule de réactions et de controverses et déplace le débat pour la musique au plan de l'éthique. Pour une société qui assumait encore les mœurs orientales de l'époque ottomane, la présence féminine sur scène représentait en quelque sorte la promotion de l'immoralité ${ }^{12}$.

En 1842, on se pose pour la première fois le problème de l'usage systématique aux spectacles de ce genre de l'italien aux dépens de la langue grecque. L'auteur anonyme d'un article publié dans le quotidien Hellinikos Paratiritis, en constatant la force du mélodrame et de l'opéra, suggère que les chanteurs italiens soient engagés à chanter en grec et que les producteurs promeuvent les opéras grecs ${ }^{13}$. Bien que le terme "grécité " ne faisait pas encore partie du vocabulaire journalistique, ni, qui plus est, de la conscience des gens, l'aspiration aux créations musicales grecques et à l'usage du grec pour les spectacles de musique sérieuse, montre la volonté de convertir la mode importée de l'Italie en un moteur de promotion de la création grecque. Le fond de cette demande est l'autonomisation de cette production par rapport à la musique italienne, une instruction appropriée pour le public, mais aussi la réservation d'une place pour les compositeurs grecs parmi leurs homologues européens. Ces aspirations sont d'ailleurs à cette époque celles de tous les domaines de l'art, ainsi que de l'éducation ${ }^{14}$. Pendant les années qui suivent, l'essor est considérable pour le théâtre néohellénique, et notamment les représentations de drame antique. Ce domaine est propice à la représentation sociale de l'hellénisme dans la diachronie, qui assure la continuité culturelle avec les idéaux antiques.

Mais le passé historique n'est certainement pas uniforme sur tout le territoire hellénique. La région de l'Heptanèse, dominée par les Vénitiens depuis 1386, suit un chemin distinct par rapport au reste de la Grèce occupée par les Ottomans, non seulement au niveau politique et économique mais surtout au niveau culturel, empruntant les styles et les structures de l'Italie voisine. Durant tout le XIX ${ }^{e}$ siècle, elle est la seule région grecque qui nourrisse des compositeurs d'envergure et jouisse d'institutions et d'infrastructures de renom.

21 Par contre, Athènes, pourtant capitale du nouvel État indépendant depuis 1834, se trouve démunie de ressources de ce genre. Les gouverneurs, les hommes d'affaires de la puissante diaspora, l'intelligentsia, enfin tous ceux qui constituent les classes dirigeantes après la Révolution, viennent s'y installer avec l'aspiration de régénérer la gloire du passé dans un lieu où foisonnent les ruines antiques et les modestes foyers d'une population multiethnique de quelque 10.000 habitants ${ }^{15}$. En attendant sa transformation en métropole, la ville se contente de l'importation de spectacles d'opéra italien et des performances de l'orchestre militaire de la Cour royale jusqu'aux dernières décennies du 
$\mathrm{XIX}^{\mathrm{e}}$ siècle, avant de voir la naissance de son premier Conservatoire, autour duquel s'organise un nouvel essor de la vie musicale.

L'annexion de l'Heptanèse à l'État grec en 1864 conduit les représentants de sa culture musicale à la capitale; deux mondes se rencontrent alors, et leur confrontation n'est pas anodine. La musique ionienne est vivement contestée pour son manque de grécité ; cette critique provenant du statu quo musical nouvellement installé à Athènes devient d'ailleurs le champ privilégié pour le développement du discours officiel sur le caractère national de l'art néohellénique. Le débat ainsi engagé atteint son apogée durant les premières décennies $\mathrm{du} \mathrm{XX}^{\mathrm{e}}$ siècle; il prend alors l'allure d'une guerre civile, dont l'écho retentit depuis dans la culture musicale grecque.

Le rôle de la presse dans cette confrontation est central. Dans un article du quotidien Paligénessia publié en 1871, l'auteur invite les compositeurs ioniens à écrire des opéras en langue grecque ${ }^{16}$. Ceux-ci ne s'y opposent pas toutefois par principe, mais ils ne peuvent trouver de librettistes ailleurs qu'en Italie ; il en est de même en outre pour les chanteurs qui peuvent prétendre à l'interprétation de leur musique. Des spectacles d'opéra en grec commencent à se monter uniquement à partir du moment de la formation des premiers chanteurs grecs et de la création des premiers chœurs vers la fin du XIX ${ }^{\mathrm{e}}$ siècle $^{17}$.

Bien que les quotidiens d'Athènes soient presque unanimes à mépriser les compositeurs ioniens pour leur «italianité », ils saluent la "grécité» de l'italien Rafael Parisini (1820-1875), lorsque ce dernier, installé à Athènes depuis 1844, présente en 1874 son Arkadion, un drame lyrique pour orchestre de vents inspiré par la révolte des Crétois contre les Turcs en $1866^{18}$. Pour Th. Synadinos ${ }^{19}$, «si cette œuvre ne présente aucune couleur grecque, elle est absolument influencée par des thèmes historiques grecs. (...) Il s'agit d'une représentation sonore de l'épopée crétoise et de l'éclatement du monastère d'Arkadion $\aleph^{20}$. Enthousiaste, le directeur du quotidien Éphiméris D. Koromilas, le lendemain de la représentation de l'œuvre (5/05/1874), déclare sa certitude que c'est ce genre d'œuvres qui peut amener à la réalisation « des rêves de plusieurs Grecs pour la création d'une musique nationale ». Dans ce dessein, Koromilas est le premier à suggérer ouvertement aux compositeurs grecs une attitude qui devient très tôt une règle : utiliser des éléments empruntés à la musique populaire dans leurs propres compositions ${ }^{21}$.

On doit signaler ici que les programmes des spectacles populaires de musique à caractère « oriental » et de musique légère occidentale ont à cette époque une place quotidienne dans la presse. Leur succès est souvent souligné par les critiques musicaux, qui ne manquent pas de le comparer avec la popularité des représentations d'opéra ${ }^{22}$. Dans les notices et les articles de la presse, ces genres musicaux très différents sont traités de manière équitable; les nuits de la capitale ont besoin d'animations de tout genre, et la critique ne prend pas la peine de hiérarchiser les styles. Pourtant le répertoire des distractions athéniennes est significatif d'un imbroglio de contradictions se référant à la fois à des conflits sociaux, à des questions d'instruction relevant de problèmes institutionnels, à des orientations idéologiques impliquant des enjeux identitaires tels que l'« européanisation » et la " grécité ». La faible qualité des productions italiennes qui défilent dans les salles de l'époque n'empêche pas une partie du public de les considérer comme un pas certain d'assimilation du mode de vie européen; les distractions populaires sont exaltées par une autre partie du même public comme confirmant l'identité grecque. La conjonction des deux tendances ne va pas de soi ; l'élite lettrée s'engage dans ce contexte à proposer un modèle de fusion des différentes contradictions 
identitaires dans un moule " national », et donc unanimement admis, à l'intérieur comme à l'extérieur des murs athéniens.

Cet engagement de l'élite lettrée est miné par tout un ensemble de bipolarités et d'incompatibilités dont la gestion demande des ressources idéologiques importantes. Ainsi la langue d'expression musicale doit suivre les préceptes du système tempéré à intervalles égaux établi en Occident; mais elle doit en même temps incorporer les traditions populaires dont la forme fluide, formée selon les règles de transmission et de diffusion orales, échappe à son éthos. Il est en outre difficile de rapprocher les fonctionnalités de styles issus de contextes sociaux complètement étrangers l'un à l'autre; pour ce faire, le caractère de la musique populaire est négligé par le discours officiel «non seulement en tant que moyen d'expression de la mentalité et de l'idéologie populaires, mais aussi comme code de communication au sein du milieu social qui les produit et les reproduit, les conserve et les fait évoluer en les adaptant au système des valeurs collectives en vigueur... $»^{23}$. Enfin, l'adoption de la langue grecque dans les livrets d'opéra, bien qu'elle donne satisfaction à une grande partie de l'audience des hautes classes, ne suffit pas pour créer l'environnement musical "grec», qui reste toujours à définir.

27 À partir des années 1870, la critique musicale se raffine : la prise de position esthétique suscite des débats entre critiques et artistes ou entre critiques représentant des opinions différentes. Les premières réactions recensées de ce type concernent un sujet qui est cher aux Grecs à peine sortis de la guerre d'Indépendance : l'identité musicale nationale, dont le premier bastion est celui de la musique ecclésiastique dite "byzantine $»^{24}$. Est-il légitime ou non d'opérer des harmonisations (à quatre voix) de ses mélodies modales? $\mathrm{Ne}$ porte-t-on pas ainsi atteinte à son caractère le plus original, débiteur de la monophonie la plus stricte? Plus qu'une question d'ordre technique, il s'agit carrément d'un défit qui revêt une importance nationale. Ce sujet provoque un grand débat, dont les dimensions

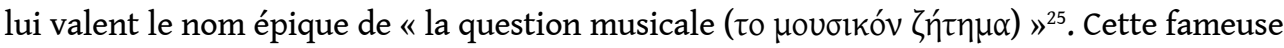
question se pose au lendemain du jour où la musique ecclésiastique adopte les règles polyphoniques (psalmodie à quatre voix) et se fait noter sur la portée. Dans le cadre des Lumières grecques, qui émanent surtout de la diaspora, les premières entreprises de ce genre débutent dans les deux églises grecques de Vienne, qui accueillent cette innovation pendant la fête de Pâques orthodoxe de 1844 avec enthousiasme ${ }^{26}$. En 1875, à Trieste, Efstathios Thérianos prend le parti contraire, défendant le caractère archaïque et monophonique de la musique byzantine et dénonçant les influences polyphoniques de provenance occidentale ${ }^{27}$.

28 À Athènes, le monde des chantres et des «Byzantinistes » ne tarde pas à s'animer à ce propos. Les pages du quotidien Éphiméris nous livrent un des moments les plus caractéristiques du débat. En 1889, I. Skylitsis ${ }^{28}$ y publie un article reprochant au chant byzantin sa monotonie, à laquelle il propose de remédier en harmonisant ses mélodies. Dans les pages du même journal, un médecin, Th. Gérogiannis, réfute avec ferveur cette thèse en défendant la monophonie byzantine, à condition qu'elle soit interprétée par de bons chantres. À l'issue de ce débat, le journal prend l'initiative de proposer la constitution d'un « conseil pour la préservation du mélos byzantin et du chant sacré ».

29 La controverse n'en finit pas; elle prend au contraire de plus en plus d'ampleur, engageant les institutions ecclésiastiques supérieures ${ }^{29}$. Mais le progrès en termes d'idées n'est pas considérable et le sujet continue à se discuter au début du $\mathrm{XX}^{\mathrm{e}}$ siècle, comme nous allons voir plus loin. 
30 La bipolarité la plus prégnante et la plus difficile à conjuguer est celle qui oppose la musique "nationale» et la musique occidentale «importée». Outre les questions évidentes d'identité, cette bipolarité s'articule aussi sur un axe opposant le savant au populaire, impliquant des considérations sociologiques, voire même de classes. A. Pétsalis ${ }^{30}$, le critique musical le plus connu du XIX ${ }^{\mathrm{e}}$ siècle, est un défenseur ardent de la musique " classique » contre la musique populaire : il considère cette dernière comme barbare, essentiellement à cause de son caractère «turco-oriental », monotone et mélancolique, produit de l'état d'esclavage, qui n'a plus lieu d'être. Il propose de faire entendre du Beethoven et du Mozart « civilisateurs », à la place des chansons populaires urbaines, qui " excitent l'âme » et font surgir de "mauvais instincts ». Chr. Vlachos ${ }^{31}$ répond à ces propos extrêmes à travers les pages de l'Éphiméris de façon sobre, portant l'essentiel de son argumentation sur le caractère éminemment grec de cette musique, dont les origines ancestrales précèdent l'occupation ottomane. Ce débat public donne une image assez typique du contexte socioculturel de l'époque. A. Petsalis représente cette classe élevée qui cherche à se rapprocher de son homologue européen en s'annexant à son environnement culturel et qui tourne volontairement le dos à un passé trop « oriental ». Cultiver la musique «classique» signifie alors appartenir au monde occidental civilisé. D'ailleurs trancher entre l'Orient et l'Occident, voilà le dilemme le plus important de la Grèce recherchant une identité moderne...

31 En 1873, l'opérette française est introduite dans la vie musicale d'Athènes. Depuis, Italiens et Français se partagent les saisons musicales : en été les premiers et en hiver les seconds 32. Quant aux Allemands, ils ne sont représentés qu'à travers les orchestres philharmoniques de la garde royale, jusqu'au moment où le réformateur du Conservatoire d'Athènes Georges Nazos, venu de Munich, impose la musique et l'esthétique allemandes en 1891.

32 Contesté pour ses connaissances en matière musicale par plusieurs compositeurs (dont la plupart étaient d'origine ionienne, comme on peut bien s'y attendre), Nazos est soutenu par la Cour, la haute société athénienne et beaucoup d'intellectuels ${ }^{33}$, dont le grand poète grec K. Palamas ${ }^{34}$. En effet, Palamas fait l'éloge de Nazos pour son travail en matière de musique et de récitation dramatique dans un article du magazine Pikili Stoa, datant de $1898^{35}$. Ainsi, le mouvement des démoticistes, qui représente les défenseurs de la culture populaire et le progressisme littéraire, se range aux côtés d'un agent institutionnel qui est accusé de cultiver l'élitisme musical et le favoritisme social. Ce n'est pas le seul paradoxe du monde musical grec en éveil ; mais il est un des plus typiques pour comprendre à quelle point les imbroglios culturels que nous avons déjà évoqués ne peuvent être compris dans une dimension unique, mais nécessitent pour le chercheur un ajustement sans cesse des angles d'approche.

33 À partir de l'année 1873, l'Éphiméris adopte une position favorable à l'opérette française. En face, le quotidien Ethnophylax défend les valeurs traditionnelles et plus particulièrement la musique, considérée en danger de disparition. Dans un article publié à Ethnophylax en $1874^{36}$, les chants et les danses populaires sont caractérisés comme des musiques « nationales », injustement supplantées par les musiques « étrangères » que les orchestres philharmoniques interprètent au cours des " concerts du dimanche », ouverts au grand public $^{37}$. L'Éphiméris riposte en défendant les stratégies de l'européanisation musicale du pays et en associant les musiques dites «nationales » aux traditions turques et arabes. On doit noter à ce propos que I. Skylitsis, collaborateur principal du quotidien et un des derniers représentants des Lumières grecques, est favorable au renouvellement 
de la musique ecclésiastique par un traitement polyphonique qui, selon lui, la rapprocherait de la tradition antique et lui permettrait de prendre ses distances avec les emprunts turcs et arabes, jugés responsables de son caractère monodique et de la monotonie de ses mélodies ${ }^{38}$.

Dans le contexte critique que nous venons d'évoquer, nous sommes surpris aujourd'hui de constater la facilité avec laquelle on se sert d'adjectifs et d'attributs à caractère ethnique, pour désigner des entités culturelles pour le moins insuffisamment définies; ceci vaut autant pour ce qui est appelé musique "nationale » ou "digne de la Grèce

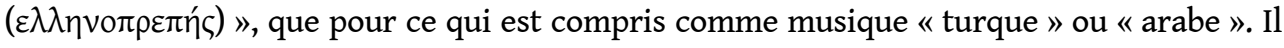
est évident que ces discours étaient destinés essentiellement à soutenir les divers champs de confrontation idéologiques, ne laissant pas de place à ce que pourrait être l'aube d'une pensée musicologique.

La première revue musicale fait son apparition à Athènes en 1871. Elle est destinée à la diffusion des manifestations du Conservatoire d'Athènes, dont il porte d'ailleurs le nom : $\Omega \delta \varepsilon$ sío $^{\mathrm{A}} \mathrm{A} \eta \eta \omega^{\prime} \mathrm{v}^{39}$. On doit attendre deux décennies encore pour voir fleurir vraiment une

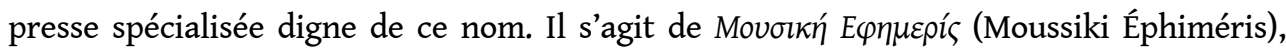
dirigée par Napoléon Lambelet ${ }^{40}$, qui se lance en 1893 pour s'éteindre 18 numéros plus tard, en 1896. Cette brève existence inaugure pourtant une nouvelle ère; l'essor de la presse musicale est désormais un fait. Pendant cette phase, qui dure jusqu'au début des années 1910, quelque dix revues musicales sont publiées, dont six à Athènes, deux à Istanbul, une à Alexandrie d'Égypte et une dans l'île de Samos ${ }^{41}$.

Parallèlement, on commence à publier les premières études sur la musique ecclésiastique, qui se multiplient vers les dernières décennies du XIX siècle. Leur sujet critique reste pendant longtemps la question de l'harmonisation du chant byzantin. Pour la première fois, ce thème est abordé par Efstathios Thérianos dans une étude publiée en $1875^{42}$. On y enregistre l'usage précoce de l'adjectif «national» pour désigner la tradition musicale orthodoxe de caractère monophonique; celle-ci est "notre musique ecclésiastique nationale ", qui répond à la musique occidentale et à son caractère polyphonique ${ }^{43}$. L'œuvre la plus importante dans ce domaine appartient toutefois à Georges I. Papadopoulos, qui publie quelques années plus tard, en 1890, le premier manuel d'histoire de la musique ecclésiastique grecque ${ }^{44}$. Dans cet ouvrage, il ne manque pas de

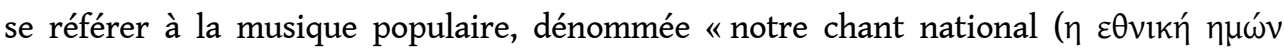
$\left.\alpha \sigma \mu \alpha \tau \omega \delta \delta^{\prime} \alpha\right) »^{45}$. L'identité «nationale » d'une œuvre musicale dépend dès lors de deux critères, celui de la langue et celui de la confession orthodoxe ${ }^{46}$. "Chaque nation ", dit-il, " possède en plus de sa propre langue, ses coutumes et ses traditions, son propre destin dans l'histoire, sa propre manière de penser et d'agir et sa propre sensibilité dans l'art et spécialement dans la musique. La musique donc, qui correspond à la nature de chaque nation, est sa propre musique nationale. Pour la nation grecque, cette dernière est constituée par la musique traditionnelle ecclésiastique et par la musique populaire $\aleph^{47}$.

Le livre de Papadopoulos introduit ainsi un des stéréotypes les plus caractéristiques en ce qui concerne la musique grecque dans sa dimension «nationale». Nous devons signaler que, avant l'introduction de l'usage du terme «national », la tradition philologique avait installé une périphrase très typique pour désigner la tradition de la culture orthodoxe: $\kappa \alpha \theta^{\prime} \eta \mu \alpha ́ \alpha$, , « selon nous », opposé visiblement à " selon eux », c'est-à-dire essentiellement la culture de la chrétienté occidentale. Pour ce qui concerne la tradition musicale ecclésiastique plus précisément, ce terme est en usage systématique à partir du XX⿳亠丷厂犬 siècle pour toute musique (ecclésiastique, séculière ou de tradition populaire) originaire des 
territoires orientaux de l'hellénisme ${ }^{48}$. Le vocabulaire qui accompagne la cause « nationale » supplante en grande partie cette expression originale, qui reste pourtant en usage jusqu'à nos jours.

L'association sous le même terme de deux versants distincts de la tradition musicale grecque, ecclésiastique savante et populaire orale, conduit progressivement à leur désignation comme un corps quasiment indissociable, portant l'empreinte de la culture hellénique dans sa diachronie historique qui engendre le présent néohellénique. Toute recherche à caractère ethnomusicologique est désormais conditionnée par cet a priori pourtant paradoxal en ce qu'il ignore l'oralité comme facteur déterminant la nature même des musiques populaires, et se permet de transposer celles-ci dans un autre contexte, celui de la tradition écrite qui soutient l'évolution du chant ecclésiastique.

Une fois cette confusion des styles installée, les deux dernières décennies du XIX ${ }^{\mathrm{e}}$ siècle sont le théâtre de la collation de la tradition populaire avec la musique savante occidentale. La fameuse "génération 1880 » dans la littérature, dominée par la personnalité de Palamas et le mouvement des démoticistes appelle l'attention du public sur les chants populaires ; leur étude est depuis un domaine à part pour la philologie grecque, mais aussi pour l'ethnographie naissante. Celle-ci prend à cette époque le nom de laographia, dont le composant «laos (peuple)» renvoie directement à son homologue «Volks » du romantisme allemand. Le fondateur de cette nouvelle discipline est Nikolaos Politis, qui consacre presque exclusivement ses recherches aux chants dits démotiques ${ }^{49}$. Ces chants à diffusion orale de l'espace rural deviennent dès lors un des chapitres privilégiés pour la désignation du caractère "national» de la culture néohellénique. Spontanés, originaux, riches dans leur diversité, ils se trouvent désormais homologués suivant les stéréotypes nationaux qui imposent ce que Hobsbawm décrit comme «l'invention de la tradition $»^{50}$.

$40 \mathrm{Au}$ moment où Palamas, Drossinis ${ }^{51}$ et A. Vlachos ${ }^{52}$ se font un devoir de restaurer l'originalité de formes mélodiques orientales comme le fameux amandé ${ }^{53}$, les défenseurs de l'européanisation lancent des discours ardents pour la «purification » de la musique populaire et pour sa « régénération » au moyen de l'adoption des principes de la musique occidentale. Le premier directeur du Conservatoire d'Athènes, A. Katakouzinos, dénonce en 1880 le retard culturel des Grecs, dû «à leur cohabitation et au métissage avec des ethnies barbares", proposant comme seul remède "la bonne musique enseignée au Conservatoire, la musique ecclésiastique adaptée à la structure polyphonique, les représentations d'opéra et les orchestres militaires $»^{54}$.

\section{$B$. Le $X X^{e}$ siècle}

\section{La littérature musicale de la première moitié du $X X X^{e}$ siècle}

41 Les sources pour la littérature musicale de la première moitié $\mathrm{du} \mathrm{XX}^{\mathrm{e}}$ siècle correspondent à deux catégories de publications :

\section{a) Revues et journaux}

Malgré son démarrage timide, la presse musicale grecque connaît un essor important à

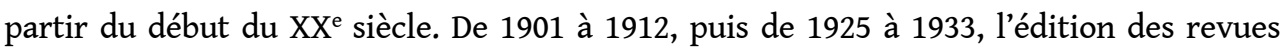
musicales est considérable. Entre les deux périodes, la suspension est justifiée à cause des 
deux guerres balkaniques (1912- 1913), la première guerre mondiale (1914-1918) et la guerre d'Asie Mineure (1921-1922).

En recensant l'activité éditoriale de la première période, nous enregistrons d'abord Forminx de 1901 à 1912, Apollon de 1904 à 1909 et Ethniki Moussa de 1909 à 1910, toutes éditées à Athènes. De 1910 à 1912, nous avons Orpheus à Alexandrie d'Égypte et de 1912 à 1915 Moussiki à Istanbul. Durant la seconde période, nous retrouvons Forminx rééditée sous le nom de Nouvelle Forminx de 1921 à 1922, Moussiki Épithéorissis de 1921 à 1922, Mousika Chronika en 1925 d'abord, puis de 1928 à 1933, Moussiki Anthodesmi en 1927, Mousikos Kosmos de 1929 à 1930, Moussiki Zoi de 1930 à 1931 et Moussiki Icho en 1933.

Pendant toutes ces années, un bon nombre de rubriques musicales s'installe de façon permanente dans les quotidiens les plus importants, ainsi que dans des revues spécialisées. C'est le cas des revues Noumas ${ }^{55}$ de 1903 à 1917 (première période), de 1918 à 1924 (deuxième période) et de 1929 à 1931 (troisième période), Héstia avant 1925 et Nouvelle Héstia de 1925 à nos jours, ainsi que des quotidiens Acropolis, Élephthéros Typos, Élephthéro Vima, Éphiméris, Éspéra, Éthnos, Kathimérini, I Kéri, Tachidromos, Tharros, Vima.

\section{b) Études et essais}

Dans l'ensemble des textes musicologiques édités en Grèce pendant la période qui nous occupe, les études et les essais sur la musique, que presque tous les grands compositeurs grecs ont rédigés, tiennent une place prépondérante. Il s'agit pour la plupart de textes concernant leur esthétique et leur idéologie propres, qu'ils ressentent le besoin de justifier par écrit, et non seulement avec leur musique. Ce sont pour nous des témoignages uniques, dans la mesure où ils sont représentatifs des tendances de leur époque dans toute leur complexité historique, et permettent de multiples voies d'approche pour l'analyse et la compréhension. Nous allons exposer ce matériel au fur et à mesure que nous avancerons dans notre exposé, dont le fil conducteur est essentiellement celui de la chronologie.

Le $\mathrm{XX}^{\mathrm{e}}$ siècle trouve le paysage musical grec considérablement amélioré par rapport à l'image qu'il donnait pendant le siècle précédent. En réalité, entre l'urgence de l'européanisation et la politique culturelle menée par la Cour bavaroise du roi Othon, la scène musicale néohellénique construit ses fondements sur l'importation de la musique classique occidentale à travers les spectacles d'opéras italiens ${ }^{56}$. Ces représentations sont données très souvent en version abrégée, voir même modifiée, à cause des incommodités plus ou moins quotidiennes et surtout à cause de l'inadaptation des salles disponibles. Malgré ces problèmes, elles sont appelées à familiariser le public athénien avec les sons européens, l'éduquer, somme toute l'européaniser comme il se doit. Parallèlement, l'enseignement musical s'organise à l'initiative des associations culturelles (notamment les premiers orchestres philharmoniques), fondées par les membres de la bonne société.

Sans que le terrain soit affranchi du vaste réseau des conflits culturels issus des circonstances historiques, à l'aube du XXe siècle, les institutions concernant la musique garantissent une nouvelle qualité de spectacles, mais aussi d'enseignement musical ${ }^{57}$. En même temps l'Opéra Hellénique ( $E \lambda \lambda \eta v i \kappa o ́ ~ \mu \varepsilon \lambda o ́ \delta \rho \alpha \mu \alpha)^{58}$ contribue à la diffusion de spectacles d'opéra (de plus en plus souvent écrits en grec), non seulement à Athènes mais aussi dans d'autres villes de la Grèce libre, ainsi que des grands centres économiques de l'hellénisme (Istanbul, Smyrne, Alexandrie, etc.). L'Orchestre de théatre du Conservatoire d'Athènes (créé par A. Katakouzinos en 1879), puis l'Orchestre des Étudiants du même établissement 
(créé par G. Nazos en 1894), préparent le terrain pour la constitution d'un vrai orchestre symphonique, qui se réalise finalement au cours des années $1920^{59}$.

Mais ces infrastructures ne suffiraient pas pour le renouvellement du paysage musical d'Athènes sans la contribution des compositeurs ioniens qui quittent leurs îles pour s'installer dans la capitale, et transformer sa culture avec leur vive participation à sa vie musicale.

\section{Les « loniens »}

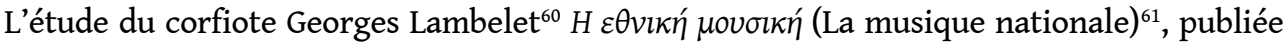
en 1901, n'est pas seulement le texte inaugurant le lancement d'une École Nationale de musique en Grèce ; il est aussi le premier essai musicologique orienté vers la musique occidentale savante. Ses idées sont plus largement explicitées dans trois livres encore ${ }^{62}$, et surtout dans plusieurs articles témoignant de sa vive activité dans le domaine de la critique musicale ${ }^{63}$. Son œuvre écrite ouvre des voies nouvelles pour les penseurs de son époque, introduisant une considération systématique, à travers la matière musicale, du problème de la considération de l'art comme facteur identitaire.

Le contenu de La musique nationale n'est pas aussi banal que l'on pense de prime abord. Il est très proche des idées des démoticistes, bien que l'auteur choisisse de s'exprimer dans la langue des puristes ${ }^{64}$. Lambelet part de la poésie et du roman néohelléniques pour parler de «création nationale ». Issu qu'il est de la culture ionienne, il exalte l'œuvre poétique de Solomos ${ }^{65}$ et de $\mathrm{Kalvos}^{66}$, dont l'inspiration par la «muse patriotique » se pose comme modèle pour les compositeurs grecs. L'œuvre artistique, dit-il, est une création "aristocratique ", portant le stigmate de la technique et du progrès intellectuel de son époque, c'est pourquoi elle revêt une valeur universelle. C'est justement cette vision globalisante qui doit à son avis être contrecarrée par l'influence de la «nature » et de l'«ambiance " grecques, qui sont appelées à lui conférer un caractère singulier et «national ». Lambelet rencontre ici l'acceptation de l'universalité de l'esprit hellénique que chérissent les démoticistes et leurs disciples, comme Périklis Giannopoulos ${ }^{67}$, dont Lambelet était très proche.

51 Dans ce même humanisme romantique évolue l'œuvre du plus illustre des compositeurs ioniens, Spyridon Samaras ${ }^{68}$, qui partage sa carrière entre la France et l'Italie. La plume de Samaras ne nous a pas laissé de textes, mais sa personnalité de compositeur est à l'origine de nombreux débats en Grèce, à cause de sa manière d'incorporer les éléments populaires dans son propre langage musical, qui est indicative de l'état d'esprit des Ioniens ${ }^{69}$. Pour ceux-ci, c'est une « ambiance » musicale qui confère aux œuvres leur grécité, ambiance qui s'installe au moyen d'emprunts folkloriques fonctionnant au sein de la composition plutôt comme citations exotiques et moins comme matière organique de base. Cette promotion de la « couleur locale » dérivant d'une « ambiance musicale rurale » laisse voir une volonté de conjugaison entre le local (dont l'extension est le national) et l'international ; ce cosmopolitisme doit beaucoup sans doute à la longue cohabitation de la culture grecque avec la culture italienne dans les îles ioniennes.

52 C'est cette « ambiance » grecque qui inspire à I. Livéralis ${ }^{70}$ sa Suite pour piano en $1847^{71}$, et à Samaras ses Scènes Orientales pour piano en $1882-83^{72}$. G. Lambelet lui-même, ainsi que D. Lavrangas ${ }^{73}$ y orientent aussi leur œuvre symphonique ; le second en parle d'ailleurs assez souvent dans ses Mémoires ${ }^{74}$. Dans tous les cas, au sein de ces figures de style tantôt classiques, tantôt romantiques ou impressionnistes, l'élément « grec » ne revendique pas 
une quelconque supériorité par rapport au traitement occidental de base. Ainsi, leur esthétique ne peut revêtir les accents épiques que l'on pourrait interpeller au profit de la prégnance de la grécité.

Un air patriotique souffle dans l'œuvre de Pavlos Karrer ${ }^{75}$, le plus romantique de tous les Ioniens, qui emprunte volontiers ses thèmes aux pages illustres de la révolution contre

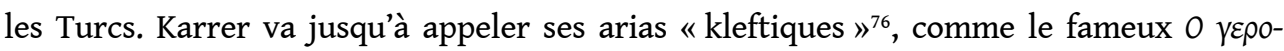
$\Delta$ ńpo (O Yéro-Dimos : Le vieux Dimos), tiré du premier acte de son opéra Markos Botsaris ${ }^{77}$. Ce goût n'affecte pas toutefois le fond de son esthétique vers des transmutations qui mettraient en cause son incontestable romantisme italianisant. Pourtant la critique a exalté Markos Botsaris pour son esprit national et le public a souvent pris son Dimos pour un chant démotique original; l'œuvre de Karrer a été comprise comme une riposte nationale à la domination de l'opéra italien. On a oublié volontiers que celui-ci avait découvert la grécité en Italie, pendant un long séjour à Milan (1850-1857), au contact de nombreux compositeurs du Risorgimento, fortement intéressés eux-mêmes par les sujets de la révolution grecque, dont l'écho retentissait encore fort dans les cercles romantiques européens ${ }^{78}$.

Lambelet, de son côté, évite les thèmes populaires dans ses œuvres en tant que compositeur. En tant que théoricien, il avance une franche proposition méthodologique : lancer une recherche systématique de la musique traditionnelle. Son modèle est l'exemple du «musicien historien » qu'il reconnaît en la personne de Grieg, regrettant le manque d'un travail analogue en Grèce: "Qu'est-ce que les mélodies démotiques deviendraient aux mains d'un Grieg grec ? $\aleph^{79}$. Pour pallier cette lacune, Lambelet publie le résultat de ses propres recherches musicologiques sur le chant démotique en $1933^{80}$. En réalité, cette publication n'est qu'une collection de chants populaires harmonisés et adaptés pour voix et piano, à l'image de la première édition de ce type, que le compositeur et musicologue français L.-A. Bourgault-Ducoudray avait effectuée en $1876^{81}$. Ce travail de Bourgault-Ducoudray a un impact considérable sur les compositeurs et musicologues grecs du début $\mathrm{du} \mathrm{XX}^{\mathrm{e}}$ siècle, ce qui conduit à la multiplication des collections de chants populaires harmonisés.

Les ouvrages les plus importants de ce type sont ceux de G. Pachtikos, $260 \Delta \eta \mu \omega ́ \delta \eta$

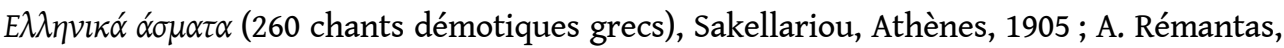

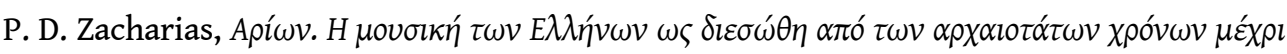

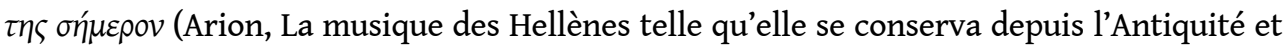

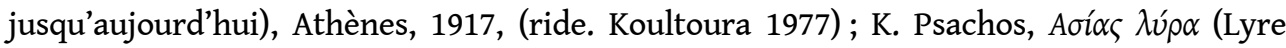

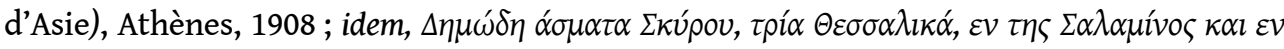

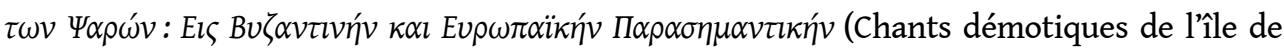
Skyros, trois de Thessalie, un de Salamine et un de Psara: En notation byzantine et

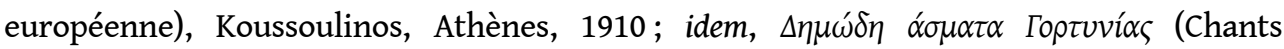
démotiques de Gortynie), Athènes, 1923; le très renommé recueil du Conservatoire d'Athènes, effectué avec les bons soins des G. Nazos, K. Psachos et A. Marsick et publié

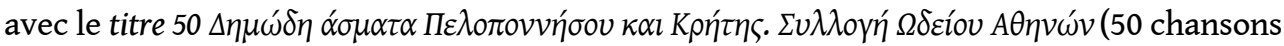
démotiques du Péloponnèse et de Crète. Collection du Conservatoire d'Athènes), Sidéris, Athènes 1930. Toutes ces collections sont précédées par des textes introductifs, qui constituent non seulement autant d'exposés méthodologiques des premières tentatives de recherches ethnomusicologiques en Grèce, mais aussi un fonds idéologique qui génère les principes conceptuels de la grécité des chants populaires. Une autre composante 
essentielle dans ces recueils de chants est le sujet de leur harmonisation, auquel nous reviendrons plus loin.

Toutes ces approches "ethnomusicologiques » sont en général très limitées sur le fond. Le peuple comme objet de recherche est circonscrit dans le rôle d'un " autre » sur lequel on articule des discours plus ou moins hégémoniques. Lambelet parle d'un «peuple non

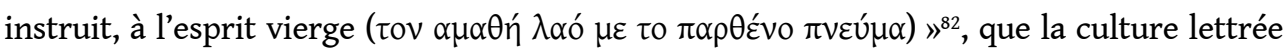
entreprend de connaître pour mettre au grand jour sa grécité originale. La complexité et les particularités multiples des traditions musicales de la paysannerie grecque, la fluidité du contenu de leur culture transmise oralement, n'attirent pas l'attention des chercheurs avant les années 1930. Au début du XXe siècle, dans les cercles des compositeurs grecs, le folklore musical grec est représenté par les transcriptions d'airs populaires souvent transformés, adaptés et même "corrigés » dans le cadre formel des mélodies savantes. Pas la moindre contestation n'est articulée dans la littérature musicologique à propos de cet usage, qui limite ses interrogations uniquement au niveau technique de l'harmonisation de chants.

\section{Une querelle « byzantine »}

57 Nous avons signalé plus haut comment, à partir du début $\mathrm{du} \mathrm{XX}^{\mathrm{e}}$ siècle, la presse quotidienne et surtout les revues musicales spécialisées réservent enfin une place notable à la culture musicale, introduisant d'importants débats autour de son identité et de son développement, qui touchent tous les genres : musique savante, ecclésiastique, populaire, etc. Durant la première décennie de ce siècle, on se préoccupe très intensément de la musique ecclésiastique et de son traitement polyphonique. C'est en effet le temps de la définition de la grécité et la musique néohellénique, populaire ou savante, devient un sujet de controverse qui saura impliquer dans ses différents aspects tous les paramètres historiques et culturels engagés dans la question identitaire. Derrière les confrontations esthétiques, on repère très vite des causes idéologiques et de nombreux enjeux qui rendent compte de l'avalanche des contradictions historiques auxquelles le nouvel État grec doit faire face. Pour pallier ces contradictions, les historiens et les anthropologues ont explicitement décrit les processus de l'invention de la tradition, la défense de la continuité historique, enfin une gestion des données culturelles qui engendre de nouvelles contradictions et pousse sur le devant de la scène historique de nouveaux enjeux.

Le débat suscité autour de la tradition byzantine reste toujours au premier rang de l'actualité musicale durant les trois premières décennies du $\mathrm{XX}^{\mathrm{e}}$ siècle et donne naissance à une énorme littérature, pour la production de laquelle des critiques, des chantres et (surtout après 1910) des compositeurs ont œuvré avec beaucoup de zèle. C'est justement dans les écrits de ces derniers que nous repérons les premiers commentaires à prétention musicologique. Nous avons déjà vu à ce propos les travaux notables de G. Lambelet ; dans le même esprit un autre compositeur important, Pétros Pétridis ${ }^{83}$ évolue vers l'érudition.

Quelques années après la publication des études de Lambelet, en 1916, Pétridis publie une série d'articles sur les questions musicologiques courantes en Grèce dans le journal grec de Londres Espéria ${ }^{84}$. Il y revient tout d'abord sur le vieux débat concernant l'harmonisation de la musique byzantine ; à la suite d'une critique fournie, garnie d'analyses et d'explications techniques, qui doit justifier son parti pris pour le traitement des mélodies byzantines, il établit même une série de méthodes indiquées pour ce 
traitement. Dans un article du 19 mai 1916 notamment, intitulé «L'harmonisation de la musique byzantine ", il pose volontairement le débat à un niveau où il ne s'était trouvé qu'occasionnellement jusqu'alors: au sein de la création savante, hors du milieu des chantres et des ecclésiastiques. Exprimant le besoin de faire évoluer cette riche tradition, qu'il considérait stagnante dans un stade primitif, il en arrive à des propositions comme l'introduction dans les églises d'un instrument polyphonique (il rappelle à ce propos que l'orgue fut une invention byzantine) et le traitement polyphonique selon le modèle occidental (du fameux hymne acathiste il ferait un motet à 4 voix, pour que cet hymne « regagne une richesse et une force d'expression nouvelles, devant lesquelles la simple monodie byzantine paraît pâle, même si elle est harmonisée à quatre voix »)

Sa thèse générale sur la musique grecque, telle qu'il la développe dans ses différents écrits, ne s'éloigne pas de cette idée essentielle du traitement de tout matériel grec selon le mode occidental, dans le dessein d'une création à caractère national. Cette aspiration appartient certes en priorité à l'École Nationale, le «groupe des quatre» selon l'expression du directeur de Noumas D. Tangopoulos, qui comptait dans son noyau dur M. Kalomiris, M. Varvoglis, E. Riadis et D. Mitropoulos ${ }^{86}$. S'il ne fait pas lui-même partie de ce noyau, Pétridis en fait l'éloge, réservant aux travaux du chef du mouvement, Manolis Kalomiris ${ }^{87}$, ses meilleures critiques. Son opinion positive a d'autant plus de poids qu'il n'est lui-même nullement engagé idéologiquement à sa manière.

Dans les principales revues de l'époque, la question de l'harmonisation du chant byzantin devient un sujet de polémique ${ }^{88}$. À travers Phorminx s'expriment les défenseurs de la modalité de la musique ecclésiastique, les «conservateurs" donc, dont les principaux représentants sont les critiques I. Tsoklis et K. Psachos ${ }^{89}$. Face à eux, I. Sakellaridis ${ }^{90}$ représente les "modernistes ", qui sont pour l'harmonisation de la musique «byzantine». Sakellaridis est le collaborateur principal de Chr. Vlachos, en tant que rédacteur de la revue Ethniki Moussa, dont ce dernier assume la direction. Vlachos est un conservateur radical, qui prend à la lettre son rôle au sein de l'Association Nationale de

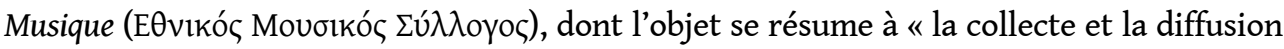
par écrit des chants nationaux et démotiques et l'étude, sur la base de ces chants, de la musique nationale, dans le but de créer de la musique hellénique authentique $»^{91}$. Sakellaridis défend autant que son directeur la modalité de la musique ecclésiastique, mais il accepte toutefois son traitement hors de la liturgie, dans le cadre de la création musicale savante. En considérant de plus près les deux fronts, conservateur et moderniste, on se rend vite compte qu'en réalité, l'espace entre les deux n'est pas aussi grand qu'il paraît initialement ; la controverse dérive finalement de rivalités personnelles plutôt que de positions immuables.

G. Pachtikos ${ }^{92}$, directeur de la revue Moussiki éditée à Istanbul, ne semble pas dérangé par l'harmonisation du chant byzantin, mais par les influences turques incorporées dans le chant ecclésiastique ${ }^{93}$. S. Stamatiadis, alias Élisséos Giannidis ${ }^{94}$, se range du côté de ceux qui soutiennent que l'harmonisation et le traitement polyphonique de la musique byzantine est indispensable pour la faire évoluer. À travers les pages de la revue Hestia, il expose ses observations sur un ton dur, mais qui a le mérite de faire le point sur l'austérité et le conservatisme exagérés dans la considération de la tradition byzantine, qui est celle de ses adversaires. On lui doit à ce propos de fines remarques, comme celle qui concerne les intervalles non tempérés, qui ne s'interprètent jamais de manière absolue, n'existant en fin de compte que dans l'imagination des traditionalistes ${ }^{95}$. Nous devons signaler que $\mathrm{G}$. Lambelet intervient lui aussi à ce sujet, en constatant que les 
intervalles inférieurs au demi-ton « représentent une valeur auditive plutôt discordante que musicale et sentimentale, au point qu'ils commencent à se raréfier, pour bientôt disparaître de notre musique populaire ». Il rattache leur existence au système enharmonique des Anciens, mais il souligne "qu'il reste à vérifier si ces intervalles ont la valeur exacte d'un quart de ton ou s'il s'agit simplement de sons chromatiques d'une hauteur variable et indéterminée, que ni la voix ni l'instrument ne peuvent rendre avec précision... ${ }^{96}$. Face à un système modal dont l'étendue dans tout l'Orient et la diachronie exceptionnelle méritent une attention plus soutenue, les considérations de Lambelet sont très pauvres, et même naïves ; mais aussi décevante est la rigidité des conformistes en la matière, qui ne voient dans ce matériel qu'un gage identitaire, et non pas une occasion de recherche et de réflexion.

K. Psachos, directeur de l'« École byzantine » du Conservatoire d'Athènes depuis 1904, riposte aux propos de Lambelet avec de longs travaux, qui lui valent une place prépondérante parmi les théoriciens de la musique du début du siècle. Jusqu'en 1919 (il sera alors contraint de démissionner de son poste au Conservatoire), dans une série d'articles et d'essais, publiés pour la plupart dans Nouvelle Phormin $x^{97}$,mais aussi dans toutes les revues importantes de l'époque, il expose une théorie très documentée sur l'interprétation de la musique byzantine, et plus précisément de l'«école de Constantinople", dont il est lui-même issu ${ }^{98}$. Il entame aussi une activité pédagogique très importante dans le cadre du Conservatoire, et ses élèves continueront à défendre ardemment ses théories après sa retraite.

Cet homme au tempérament pléthorique est aussi le premier à entreprendre systématiquement une activité ethnomusicologique. Assisté par G. Nazos et le directeur de l'orchestre du Conservatoire Armand Marcik, il organise des missions de collecte de chants démotiques, dont le fruit est publié dans la «Collection du Conservatoire d'Athènes ${ }^{99}$. Si son activité de musicologue connaît un succès important et lui procure une notoriété indéniable, il n'en va pas de même avec son activité de compositeur, qui est fortement contestée, notamment par Sophia Spanoudi, une des personnalités les plus importantes de la critique musicale après les années 1930, dont nous allons parler plus loin.

65 Le principal adversaire de Psachos au cours de années 1910-20 est I. Sakellaridis. Répondant à l'étude de Psachos intitulée Liturgie (éd. Kassoulinos, Athènes 1909), Sakellaridis publie en 1910 dans Ethniki Moussa un article que l'on pourrait considérer comme le manifeste des «modernistes». Ces derniers, on le devine facilement, ont eu d'ailleurs souvent l'occasion de se montrer aussi extrémistes que les "conservateurs", qui en arrivent à demander l'intervention du Saint-Synode et du patriarche en personne pour exclure toute tentative d'innovation, du moins dans le domaine liturgique ${ }^{100}$.

Nous avons déjà signalé, dans le contexte de l'élaboration de la culture néohellénique, la tendance courante à la formation de bipolarités, juxtaposant dans le même schème des entités conceptuelles plus ou moins figées en des poncifs, eux-mêmes capables d'engendrer de nouvelles bipolarités. Dans un tel schéma, la musique ecclésiastique est représentée comme l'expression "authentique » de l'élément "oriental» du passé historique de la Grèce, face à l'intrusion de la nouveauté occidentale, qui n'était pas facilement récupérable dans le contexte de l'identité nationale. Elle rivalise dans ce rôle avec la musique populaire, montrant une autre bipolarité : elle doit laisser son caractère « oriental » pour retrouver le juste degré de grécité. Car si dans le cas de la musique ecclésiastique la référence historique remonte à Byzance, pour celui de la musique 
populaire, elle relève de la domination ottomane. Ceci peut expliquer en partie pourquoi le traitement polyphonique est accusé fortement de dénaturer la modalité innée de la musique ecclésiastique, tandis que l'harmonisation des chants populaires est universellement interprétée comme un processus naturel de son développement musical. L'introduction de la cause sociale rend encore plus complexe notre schéma: il est intolérable que la forme de l'expression musicale « savante » de la tradition ecclésiastique soit modifiée, mais il est indiscutable de laisser sans enrichissement l'expression musicale du peuple «non instruit ».

Dans aucun cas, on ne s'interroge sur l'autonomie structurale et l'autarcie expressive de ces formes musicales. Le problème se pose en termes d'adaptation au langage musical occidental et à ses formes expressives. Comme le développement musical en Grèce est alors associé au processus de l'européanisation, l'incorporation de la tradition musicale grecque (ecclésiastique, séculière, populaire, etc.) dans la création musicale savante demeure la seule préoccupation des compositeurs et des théoriciens. Sur cette préoccupation vient se greffer la requête de la grécité, qui détermine les principes d'évaluation des sources de la tradition musicale, son corps et bien sûr son traitement.

\section{G. Nazos et le Conservatoire d'Athènes}

68 Le rôle des institutions est crucial dans le développement des interactions entre les différents agents de la vie musicale de la capitale. Depuis 1891, date à laquelle G. Nazos est convoqué de Munich pour réformer et diriger le Conservatoire d'Athènes, cet établissement devient au fur et à mesure un organisme très puissant. Son pouvoir se fait sentir non seulement dans le milieu musical athénien, mais dans l'agencement global de la politique institutionnelle centrale, concernant l'enseignement musical de tous les niveaux. Le poste de directeur du Conservatoire acquiert dans ce cadre un poids politique considérable et Nazos devient un conseilleur gouvernemental, qui administre l'institutionnalisation musicale du pays.

Le Conservatoire d'Athènes, haut lieu de la nouvelle intelligentsia athénienne, devient à la fin de la première décennie du $\mathrm{XX}^{\mathrm{e}}$ siècle l'arène d'une vraie guerre civile musicale qui oppose les Athéniens aux Ioniens. Les accrochages commencent à cause de l'exclusion systématique des compositeurs ioniens de ses rangs, à l'initiative de Nazos. La situation s'aggrave quand Kalomiris, à son arrivée à Athènes en 1910, prend place aux côtés de Nazos, soutenu aussi par les démoticistes en bloc. À travers les pages de Noumas, la revue historique de ces derniers, les Ioniens et Samaras en particulier sont accusés de ne pas communier avec la culture grecque, d'être «italiens». La partie adverse engage G. Lambelet pour sa défense. Elle divulgue des rumeurs selon lesquelles le célèbre Samaras rentrerait au pays pour prendre le poste de directeur du Conservatoire, ce qui jette de l'huile sur un feu déjà bien allumé, et provoque une vague d'expressions d'hostilité à l'égard de la personne de Samaras, bien que celui-ci n'eusse jamais la moindre participation aux faits ${ }^{101}$. L'histoire et les conséquences de cette vive polémique dépassent largement le cadre de cet article et mériteraient une étude à part; nous nous bornerons ici à ses aspects les plus significatifs.

70 Les écrits de G. Lambelet, à travers les pages de la revue Kritiki ${ }^{102}$,dont il est le directeur avec le compositeur et critique musical G. Axiotis, élèvent un front idéologique contre la politique de Nazos au sein du Conservatoire; plus que cela, ils constituent un vrai manifeste pour une esthétique musicale à caractère grec et pour un renouveau de la 
musique néohellénique. La plume de Lambelet se fait souvent violente pour critiquer cet homme très puissant et très conservateur, et sa conception élitiste d'une culture musicale réservée à la bonne société athénienne et à l'aristocratie étrangère qui faisait partie de l'entourage royal.

G. Axiotis ${ }^{103}$ se range aux côtés de Lambelet dans ce débat, y apportant sa contribution sous forme de lettres adressées au Conservatoire; sa critique est particulièrement dure à propos du baryton Aramis ${ }^{104}$, qui interprétait depuis 1903 des chansons folkloriques arrangées selon le modèle des lieder romantiques ${ }^{105}$, avec le fort appui de Nazos, l'organisateur de ces concerts. Axiotis, ennemi juré de ce dernier, ne se limite pas à une confrontation personnelle; sa plume ironique se dresse aussi contre l'attitude de la presse et du public, qui en fin de compte se satisfaisaient plus du savoir-vivre de la "bonne société " que d'une adhésion esthétique à proprement parler. Axiotis fait également le compte des conséquences de l'initiative de Nazos pour une «germanisation» du répertoire, ce qui provoque l'essor démesuré des classes de piano réservées essentiellement aux jeunes filles de la bonne société, au détriment de la variété des instruments de l'orchestre. Le piano, à cause de son coût élevé mais surtout grâce à son répertoire qui favorise les solistes, convenait parfaitement à la condition financière et aux principes moraux de cette classe sociale. Lambelet, pour sa part, pense que les Grecs ne sont pas encore prêts à apprécier la musique de Bach et de Beethoven, et que la promotion de cette musique auprès des jeunes étudiants ne tient qu'à la vanité des enseignants du Conservatoire, répondant à un courant de mode plutôt qu'à un vrai plan pédagogique.

Derrière ces objections de Lambelet à l'importation de la culture allemande, se cache l'angoisse de l'homme qui se fait écarter par des gens de pouvoir le jugeant incapable d'apprécier cette musique « exigeante » et « sérieuse ». L'ironie est que cette dépréciation de son éducation « légère » car italienne vient de personnes qui n'ont pas forcément sa profonde culture musicale; d'hommes de pouvoir qui montent leur jeu sur des critères très éloignés de l'aspiration sincère des Ioniens à une assimilation progressive de la musique européenne par les Grecs.

On voit facilement que les implications de ce débat sont trop importantes pour se limiter à la simple confrontation personnelle, et la chaîne des réactions continue : le directeur du quotidien Acropolis Vl. Gavriilidis prend la défense d'Aramis, déclarant que sa collection des chants démotiques "marque l'aube de la musique grecque savante $»^{106}$. Cette déclaration provoque la colère non seulement d'Axiotis, mais aussi de Chr. Vlachos, qui caractérise comme "impardonnables" les interventions arbitraires d'Aramis dans le corpus folklorique. Dans un long article, publié en 1903 dans Phorminx, il ne manque pas de s'en prendre aussi à l'attitude de la bonne société et du couple royal, qui gênait tant Axiotis avec son goût pompeux et exubérant ${ }^{107}$. À travers les interventions d'Axiotis et de Vlachos nous enregistrons les premières réflexions concernant l'esthétique de l'interprétation et de l'adaptation de chants populaires. Axiotis et Vlachos revêtent le rôle des spécialistes autochtones accusant l'« étranger » Aramis de promouvoir des versions « occidentalisées » des chants démotiques. Derrière ces confrontations, il est clair que la question de la création de la « musique nationale » s'associe définitivement à la tradition démotique, qui se présente comme la source nationale la plus authentique et incontestable. G. Lambelet, avec son étude sur le sujet, fait figure de pionnier et les Ioniens ne cessent de s'y référer ; Axiotis propose même qu'elle soit prise comme archétype et modèle. 
Il est évident que les rivalités personnelles sont pour beaucoup dans la polémique entre les différentes parties qui se disputent l'appropriation de la tradition musicale dans tel ou tel cadre. La question de base dans leurs confrontations concerne uniquement l'esthétique de son adaptation et de son incorporation dans les œuvres savantes. Selon les dires de Vlachos, «les chants démotiques doivent être adaptés, étant donné que leur reproduction fidèle risquerait de provoquer de la monotonie quant au résultat sonore ${ }^{108}$ . L'étude de ce matériel ne préoccupe aucune des parties impliquées, et l'essentiel de sa nature, son évolution, sa fonctionnalité et sa diffusion restent inconnus même aux chercheurs qui prétendent le défendre. Le débat évoluant au niveau de l'esthétique de l'adaptation et de l'incorporation des chants populaires couvre comme nous avons vu un monde complexe de stratégies culturelles: celle du "germanisme» de Nazos contre l'« italianisme » des Ioniens ou celle de l'« européanisme » d'Aramis contre le "grécise » des autochtones. Mais en réalité, la querelle des styles n'est qu'un prétexte; le champ musical est un champ fertile où se cultivent toutes sortes d'ambitions personnelles durant les premières décennies du $\mathrm{XX}^{\mathrm{e}}$ siècle ${ }^{109}$.

Ce tumulte de consonances et de dissonances touche un crescendo impressionnant à 1908, avec l'arrivée à Athènes d'un jeune compositeur rayonnant, Manolis Kalomiris, né à Smyrne et formé d'abord à Vienne, puis à Kharkov en Ukraine. Très doué pour les relations publiques, Kalomiris trouble le public athénien avec son fameux "manifeste » pour le lancement d'une "École Nationale » ${ }^{110}$, diffusé dans le programme de son premier concert grec. Ce texte introduisant en pompe le nationalisme musical défraie la chronique entre 1908 et 1910 à travers les pages de Noumas ; il provoque vite l'implication des gens de lettres, et notamment des démoticistes, qui l'associent à leur propre cause ${ }^{111}$. Cette alliance n'est pas spontanée; Kalomiris, depuis Kharkov déjà, noue de solides relations avec l'équipe de rédaction de Noumas et de son directeur D. Tangopoulos en personne.

Kalomiris fait ainsi sa propre révolution sur un terrain préparé d'avance. Son manifeste, rédigé évidemment en langue démotique, est pré publié quatre jours avant le concert dans les pages de Noumas, provoquant la colère des puristes ${ }^{112}$. Gr. Xénopoulos ${ }^{113} \mathrm{y}$ diagnostique la "perversion linguistique » du nouveau venu, qui affecterait sans doute son talent de compositeur et ses œuvres ${ }^{114}$. Kalomiris répond sur un ton grave qu'il lui est préférable d'honorer son ethnie que sa personne : « Nous (i.e. les démoticistes), plus que de notre gloire personnelle, nous rêvons de voir l'école grecque, l'école roméique ${ }^{115}$, faire partie de l'histoire de la musique universelle ». Dès ses premiers écrits, ses flèches visent droit Samaras, ce qui lui fait prendre une position consciente dans le grand débat qui animait alors Athènes. Le succès international de Samaras est un drapeau rouge pour Kalomiris qui voit en lui le grand adversaire dans son ambition de dominer la scène musicale grecque ${ }^{116}$.

En 1909, un an après le concert de Kalomiris, Th. Synadinos écrit un article dans Noumas ${ }^{117}$ pour riposter à l'avalanche de publications contre Nazos, accusé d'avoir mis les Ioniens à la porte du Conservatoire. Synadinos, auteur de la première Histoire de la musique néohellénique, critique musical et membre de la bonne société d'Athènes, s'empresse de féliciter Nazos pour ses mesures et crédite les Ioniens de l'« italianisation » de la musique néohellénique. Dès lors, l'« école ionienne » est définitivement qualifiée comme annexe du romantisme italien, et se trouve exclue de l'histoire officielle de la musique nationale.

78 En tête de file de ceux qui protestent contre ces thèses figurent G. Lambelet et G. Axiotis, co-directeurs du journal Kritiki ${ }^{118}$. Lambelet publie aussi dans le quotidien I Kéri, sous le 


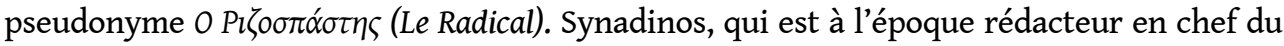
quotidien Acropolis, introduit dans le débat des nuances politiques, en associant au sujet les réactions à la révolution de $1909^{119}$. Son texte est un véritable libelle contre les compositeurs ioniens, inculpés d'avoir banni de leur horizon créatif le caractère grec. Usant d'un langage dur et plein d'ironie, il accuse les membres de la famille Lambelet de ne pas avoir pu s'élever à la dignité d'être Grecs : « Un personnage qui se prétend radical insulte depuis quelques jours le Conservatoire de ne pas avoir cultivé notre musique nationale. C'est la faute du Conservatoire si Napoléon Lambelet n'a pu être ni italien, ni français, ni allemand, ni juif, ni grec dans l'âme et le cœur? Toute sa créativité ne comporte qu'une dizaine de chansonnettes qui ne se comparent même pas à une seule composition de Kalomiris. Est-ce la faute du Conservatoire si G. Lambelet, bien qu'il ne soit pas né pour être musicien, l'est devenu? Si Nazos n'a pas recruté G. Lambelet, cela ne veut pas dire qu'il est mishellène. Lui permettre de le recruter pour aveugler les élèves? Il pourrait alors en effet être accusé comme mishellène. Nous prônons la révolution. Nous envisageons le nettoyage. Nous ne réussirons jamais si nous ne commençons pas par certains radicaux $»^{120}$. Il est évident que dans une confrontation impétueuse l'argumentation est limitée, mais sans raisonnement de fond. L'urgence de faire tomber les adversaires idéologiques se déclare sur un ton plein d'intolérance; la recherche et la prise de conscience des réalités et des enjeux effectifs n'a aucune place dans cette guerre, qui profite aux intérêts et qui ensevelit les idées. Le nationalisme y devient un instrument brut d'outrage ; la requête impérieuse de la grécité est ici un prétexte voilant un contenu nuageux de qualités mythifiées avant même d'être définies.

Un mois après et toujours à travers les pages de Noumas, un autre jeune compositeur intervient, cette fois-ci de Paris. Il s'agit de Marios Varvoglis ${ }^{121}$, qui embrasse pour la plupart les thèses de Synadinos, tout en étant plus modéré et plus retenu dans ses propos fulgurants. Visiblement adressée à Lambelet, sa critique anonyme vise ceux qui « passent deux - trois années en Italie où l'on ne connaît rien à la musique complexe, puis retournent en Grèce pour entreprendre la tactique de décrier, sans avoir à présenter une mesure de musique de bonne conscience». Mantzaros aussi est caractérisé «italien jusqu'à l'os, imitateur de l'art bavard de Rossini ", qui ne ressent point l'esprit roméique, car s'il l'avait effectivement ressenti, « on disposerait depuis longtemps de la musique nationale, comme nous disposons de la poésie nationale ». Quant à Samaras, il est lui aussi traité d'imitateur, cette fois-ci des «sucreries» de Puccini et de Mascagni. La plume critique de Varvoglis (s'exprimant évidemment en démotique) atteint aussi les établissements musicaux grecs, mais elle ne réserve que des louanges à Nazos et Kalomiris. Tous ses espoirs vont à la nouvelle génération de compositeurs grecs, qui assurent leur formation dans les grands centres européens et qui « ne tarderont pas à montrer leur taille à Athènes $»^{122}$.

80 Varvoglis ne fait pas suivre ses réactions ainsi exprimées d'une argumentation qui dépasserait le niveau des confrontations impliquant les personnalités du milieu. Si l'on compare toutefois l'esthétique de ses œuvres à celle de Kalomiris et de Lambelet, on est obligé de reconnaître des affinités avec cette dernière, objet de ses flèches. Il semble que c'est son engagement démoticiste qui le pousse à défendre Kalomiris contre les «Italiens »; dans tous les cas, le débat musicologique à proprement parler reste toujours dans le même état d'indigence.

81 La confiance que Varvoglis réserve au Conservatoire est bien sûr pleinement partagée par Kalomiris, qui répond à son tour à Synadinos, un mois après la publication du texte de 
Varvoglis, le 31 janvier $1910^{123}$. Il réside alors toujours à Kharkov, mais il se sent tellement concerné par les affaires grecques, qu'il affirme avec une certitude surprenante que le Conservatoire est équivalent à ses homologues européens et qu'il représente une institution qui «honore l'hellénisme». Diplomate doué, il a un geste de courtoisie pour Nazos, qu'il ne manque pas de tourner en une réflexion désobligeante pour Samaras : « $\mathrm{Si}$ l'on pense quel chaos régnait au Conservatoire avant Nazos, toute critique s'évapore et il ne reste que son grand et honnête travail d'organisateur ». Et plus loin : «Qui serait digne de succéder à M. Nazos ? Personne. Vous me direz, peut-être M. Samaras. Mais je crois personnellement que, s'il est vrai que M. Samaras occupe la place extraordinaire dans la musique internationale que l'on imagine en Grèce, il n'acceptera jamais de renoncer à une si brillante carrière à l'étranger pour venir s'installer à jamais à Athènes (...) Vous me direz qu'il le ferait par patriotisme. Oui, mais pour croire à ce patriotisme, il doit nous le faire voir dans quelque grande et sérieuse œuvre en langue grecque et aux couleurs grecques ». En homme qui pense sérieusement ses stratégies, Kalomiris ne laisse pas tomber à l'eau l'attitude amène de Varvoglis : «Si la grécité compte deux musiciens qui sentent ce que ce mot veut dire et qui luttent pour une musique Nationale et un art National, ces deux musiciens, ce sont Varvoglis et moi-même. Nous avons embrassé tous les deux notre philologie Nationale et notre langue Nationale, tous deux démoticistes... » 124 .

Ses complicités ouvrent finalement la voie pour que Kalomiris s'installe à Athènes en 1910, chargé d'assurer les classes de piano, d'écriture, de contrepoint, de composition et d'histoire de la musique au Conservatoire. Par contre Samaras, revenu en Grèce un an plus tard, en 1911, est définitivement écarté de l'accès à ces disciplines, malgré sa haute qualification. Mais la personnalité de Kalomiris est trop forte pour lui permettre de cohabiter au sein de la même institution avec l'homme ambitieux qu'est Georges Nazos. Les deux hommes finissent par entrer dans un conflit farouche, qui conduit Kalomiris à quitter le Conservatoire en 1919 pour fonder le Conservatoire Hellénique ${ }^{125}$.

Dès lors, le Conservatoire d'Athènes est de plus en plus violemment critiqué par les compositeurs appartenant au mouvement de l'École Nationale. Dionysios Lavrangas, Manolis Kalomiris et Marios Varvoglis, avec leurs articles attaquent son directeur en mettant en avant chacun des arguments différents. Varvoglis s'arrête au préjugé scandaleux qui conduit à l'exclusion des compositeurs grecs des postes d'enseignants au profit des professeurs étrangers. La démission de Lavrangas contestant également la politique de Nazos laisse une vive impression. En somme, l'École Nationale découvre après coup le conservatisme du Conservatoire et s'indigne de son programme d'études jugé très partiel dans son orientation exclusivement germanique, puis exclusivement française.

Toute cette polémique inaugure un esprit critique inconnu jusqu'alors envers les institutions; mais on ne doit pas ignorer toutefois combien celui-ci reste lié à une attitude sociopsychologique de l'ensemble de l'élite des nouveaux compositeurs grecs qui cherchaient à se justifier, voire même à s'imposer. La requête d'une réforme musicale caresse les oreilles des intellectuels et du public; l'engagement dans la juste cause nationale justifie les verbes les plus violents; mais les stratégies qui interpellent ces clauses laissent de côté les conditions historiques, la réalité sociale et le contexte culturel de l'époque. Inévitablement, les confrontations restent au niveau de disputes personnelles sans issue, étant donné l'absence de conscience et d'instruction qui pourraient les véhiculer dans des canaux d'action plus efficaces. En Grèce au début du XX ${ }^{\mathrm{e}}$ 
siècle, toute position et toute ambition personnelle, aussi motivée soit-elle, se perd dans un cadre complexe où le pluralisme des opinions ne permet pas la constitution de vrais courants de pensée, dotés d'un pouvoir d'influence et d'intervention au statu quo sociopolitique. Ainsi le monde musical grec se fixe sur l'idéologie principale d'une musique nationale, dont le processus complexe d'élaboration a lieu dans le sein des institutions aussi bien qu'à leur insu, puisque sa forte charge idéologique dépasse finalement le stricte cadre de celles-ci.

Avec le temps, et malgré l'amélioration du niveau de l'enseignement musical, le Conservatoire d'Athènes se montre incapable de soutenir la libre évolution de la production artistique en Grèce et se replie dans le rôle du défenseur d'un système pédagogique rigide, tributaire des convenances sociales. La musique "classique " (et l'éducation musicale en général) devient une occupation de luxe, l'affaire de la bonne société athénienne, et n'atteint point le large public. En outre, l'orientation « européenne » de la nouvelle classe supérieure, qui se développe à la lisière de la cour royale, dicte la vénération de la production musicale occidentale et le mépris de toute expression musicale indigène.

$86 \mathrm{Au}$ fur et à mesure, deux camps opposés se forment : les conservateurs « professeurs de musique » (du Conservatoire) face aux progressistes « compositeurs ", prédicateurs de la rénovation musicale. Abandonnant son ancienne attitude, Kalomiris et son cercle sont à la fin des années 1910 en tête du front d'opposition au statu quo musical que représentait le Conservatoire d'Athènes et l'intelligentsia qui lui était associée. L'objection des "nationalistes " se manifeste encore une fois sous forme de critique dans la presse de l'époque et déclenche une nouvelle chaîne de réactions, provoquant d'abord la démission de plusieurs professeurs du Conservatoire, puis la création d'autres conservatoires. À partir des années vingt, ces derniers accueillent d'importantes personnalités de la vie musicale grecque ; mais l'immobilisation des premières institutions dans des conflits sans fruits et sans fin marque à jamais la culture musicale néohellénique.

\section{Kalomiris et le mouvement de l'École Nationale}

87 La fondation du mouvement de l'École Nationale de musique par Kalomiris, comme nous l'avons déjà remarqué, est le fruit d'une stratégie de longue haleine. G. Lambelet avec son article de 1901 et D. Lavrangas avec ses premières œuvres sont en réalité les premiers à lancer cette cause ; mais leurs initiatives n'aboutissent pas à un courant à proprement parler. Kalomiris, par contre, bien qu'il ne participe pas physiquement à la vie musicale d'Athènes, a su guider son instinct à travers les évolutions culturelles contemporaines et nouer une alliance critique avec les démoticistes ${ }^{126}$. Ce faisant, le jeune compositeur a pu non seulement profiter de leur appui, mais surtout construire son propre rôle comme leur homologue dans le domaine musical.

Tandis qu'il réside encore en Ukraine, Kalomiris s'abonne à Noumas, et entretient une correspondance régulière avec son directeur $\mathrm{D}$. Taggopoulos, ainsi qu'avec les personnalités littéraires du mouvement, Psycharis, Ephtaliotis et Palamas lui-même ${ }^{127}$. Quand l'heure sonne pour son premier concert à Athènes en 1908, il sait que son entrée en scène ne doit pas être discrète ; il rédige donc le texte de son programme comme une confession esthétique et idéologique, y engageant les principes démoticistes en faveur de la proclamation de l'École nationale de musique. La pré-publication dans les pages de Noumas accorde à ce texte des dimensions de «manifeste " et à son auteur l'onction de 
leader. En l'espace d'une semaine, le jeune compositeur de 25 ans réussit à s'imposer comme le Messie de la musique néohellénique, convoitant un rôle analogue à celui que son idole, Palamas, tenait dans le domaine de la littérature ${ }^{128}$.

Ce texte marque l'histoire de la musique savante grecque, influençant toutes les évolutions musicales qui suivent. Kalomiris s'engage dans un rôle hégémonique dans la vie musicale et l'éducation qui en relève, montrant un vrai talent pour se retourner dans les conditions culturelles et politiques instables de la première moitié du $\mathrm{XX}^{\mathrm{e}}$ siècle en Grèce. Mais le fond de ses thèses concernant l'identité musicale grecque n'évolue pas véritablement durant son activité cinquantenaire dans ce domaine. Les mêmes idées sont identifiées d'ailleurs dans l'ensemble de ses nombreux écrits, essais, textes de conférences, critiques musicales, commentaires, etc. Dans cet ensemble opulent, il revient souvent aux questions de théorie et de pédagogie musicale, se donnant la mission de faire connaître la musique grecque, populaire et savante. Un sujet qui lui est cher est celui de la relation entre la poésie et la musique; il souhaiterait une musique pouvant exprimer l'âme grecque aussi bien que la poésie contemporaine (c'est un grand amateur de Palamas) ou démotique, et il incite les jeunes compositeurs à y chercher l'inspiration ${ }^{129}$. La même question est reprise dans son Traité sur les formes musicales ${ }^{130}$, à propos de la mise en musique de la poésie. Depuis, ce livre a servi comme manuel à plusieurs générations d'étudiants de musique, tout comme son Traité d'harmonie ${ }^{131}$, où il n'omet pas de rédiger un chapitre sur les modes grecs (anciens, byzantins et démotiques) et leurs lois harmoniques. Enfin, dans ses Mémoires ${ }^{132}$, il s'explique entre autres pour ce qui concerne Nazos et le Conservatoire d'Athènes, pour son désaccord avec les harmonisations du chant byzantin de Psachos, ainsi que pour son fameux « manifeste » de l'École Nationale.

À travers toute son œuvre, Kalomiris prône une musique nouvelle, issue de la prise en considération de la tradition populaire. Le savoir-faire compositionnel est à rechercher dans les grands moments de la culture musicale européenne; la tradition populaire, quant à elle, doit offrir le parfum de l'authenticité qui émane de son originalité nationale, renfermant le germe de toute la grandeur diachronique de l'hellénisme. Dans cette conception de l'École nationale, il ne s'écarte pas au fond des intentions d'un Lambelet; il refuse toutefois d'accorder quelque valeur qui soit aux initiatives des Ioniens et déplore leur attachement à la culture italienne ${ }^{133}$, bien qu'il ne dédaigne pas d'autres expressions de nationalisme musical provenant de la périphérie européenne, comme celle de la Norvège.

91 Pour ce qui est de l'exploitation des trésors cachés de la tradition populaire, Kalomiris procède avec méthode : éviter l'emprunt direct aux mélodies populaires et se cantonner à l'utilisation du rythme, des gammes et du «caractère» de la chanson démotique. Le grand problème de l'adaptation et de l'harmonisation des mélodies populaires qui primait dans la réflexion de Lambelet est esquivé ${ }^{134}$; comme ce sujet était directement lié à la

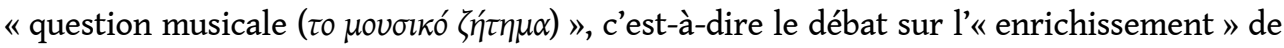
la musique byzantine par des techniques polyphoniques, Kalomiris préfère le passer sous silence.

92 En renonçant à l'emprunt systématique aux mélodies populaires ${ }^{135}$, Kalomiris se démarque d'une attitude courante parmi les compositeurs grecs de l'époque, qui consistait à produire des arrangements-adaptations d'airs populaires pour piano, ou chant et piano. Depuis la fin du XIX ${ }^{e}$ siècle, ce traitement était très à la mode; de sorte que, au début du XXe siècle, un répertoire important de ce genre se réservait une place d'honneur dans tous les concerts de musique savante à Athènes ${ }^{136}$. Lambelet devance la 
critique de Kalomiris, en écrivant à propos de ces compositeurs qu'» ils se limitent à l'imitation du chant populaire par des moyens techniques primitifs et médiocres $»^{137}$.

Kalomiris prend le devant toutefois en se tournant vers le " groupe des cinq Russes » pour chercher un prototype esthétique et une légitimation théorique; ses emprunts sont néanmoins sélectifs, négligeant le cosmopolitisme musical de l'œuvre de Tchaïkovski et de Rubinstein et restant accroché à une forte aspiration à exprimer ou plutôt à révéler "l'âme nationale». La promotion d'une esthétique "moderne» signifie pour lui l'abandon de l'exploitation des mélodies populaires comme des éléments "exotiques" (tendance qu'il reproche à l'école ionienne) au profit d'une "vraie musique nationale ", qui doit être liée à la "vraie langue du peuple » et à sa vitalité. Ce " grand chemin de la vérité » dont il se fait l'apôtre transpose dans le domaine musical le moto principal du mouvement des démoticistes dénonçant la « fausse et artificielle langue des puristes ». En termes de musicologie, il est difficile de rendre compte de ce que comporte cette "grécité » et de ce en quoi elle révèle l'«âme grecque " installée dans les discours à l'image du Volksgeist romantique. La raison en est que cette définition n'est pas un souci pour Kalomiris, ni pour ses autres défenseurs; l'idéologie qu'elle recouvre, dans toutes ses nuances, convient mieux à une conception quasiment mystique, abstraite et fluide, qui assure sa dimension diachronique. Le recours à une telle valeur universelle offre un refuge sûr et stable pendant la quête de l'identité nationale par temps de précarité économique et politique. Les deux grands adversaires de la scène musicale grecque, Lambelet et Kalomiris, au moment où ils tiennent à confirmer leur divergence, basent leurs propres arguments sur les mêmes expressions abstraites ("âme grecque ", " caractère grec », « environnement grec », « vitalité du peuple »), qui semblent découler plutôt d'un idéal quasiment onirique que d'une connaissance bien fondée du terrain sur lequel ils s'engagent: la culture grecque qui leur est contemporaine. Dépouillée de rigueur, cette approche finit par trahir ses desseins premiers, en laissant les choix esthétiques sans réel fondement, si ce n'est la voix d'un instinct patriotique chargé d'un ample inconscient passéiste et doté d'une très faible conscience historique.

Le champ des débats autour de la musique nationale réserve une place prépondérante au sujet du chant démotique et de la tradition populaire en général. La laographie naissante assure les concepts de base pour son approche, qui relève des principes primordiaux du romantisme germanique. Kalomiris les prend à son compte pour les installer à son tour, sans l'ombre d'une contestation, dans le discours musicologique et surtout dans l'enseignement. Son apport personnel à la recherche et à l'étude de ce matériel est strictement limité à ce cadre restreint. En ce qui concerne le côté plus « technique » de la question, il consacre plusieurs pages aux modes grecs dans son traité d'harmonie, avec une analyse qui rencontre l'esprit de Lambelet; le dernier réserve en plus une forte critique pour l'étude de Bourgault-Ducoudray, et plus précisément pour ses harmonisations de chants populaires grecs.

Lambelet se démarque toutefois sensiblement de l'École nationale, en se consacrant systématiquement à la collecte de chants populaires, à l'étude de leurs principes modaux et au développement des questions d'harmonisation. Il s'y met avec sa qualité de compositeur - créateur, qui donne la priorité à l'analyse technique, ce qui lui permet d'incorporer par la suite le matériel ainsi examiné dans ses propres créations. Ses thèses sur la théorie, les "justes" harmonisations et adaptations polyphoniques des chants populaires, constituent une sorte de «manuel » de l'école nationale. L'aspect historique ou fonctionnel de la musique populaire ne l'intéresse point, car Lambelet est issu d'une 
vieille culture savante, qui, contrairement à Kalomiris, entend le romantisme dans sa dimension universelle en s'abstenant d'une exploitation idéologique à caractère patriotique. Kalomiris, emporté par les tensions politiques de son temps, aspire à la renaissance musicale à l'image de la renaissance nationale et transpose son parti pris pour la Grande Idée en engagement fervent pour la Grande Idée musicale. Dès lors, le domaine de l'École nationale est plus clairement circonscrit et appelle à la mobilisation sous une bannière nationaliste qui ne laisse pas beaucoup de place à l'autonomie artistique : le compositeur doit être avant tout un serviteur de la cause nationale.

Une fois cette position prise, on comprend mieux comment Kalomiris entend l'affirmation d'un rôle hégémonique de la tradition musicale : «Le rayonnement de la musique grecque, tant pendant les années glorieuses d'Alexandre le Grand que plus tard, avec la gloire et la réputation de la musique byzantine ecclésiastique et la civilisation musicale supérieure du peuple grec, a bien davantage influencé la musique des peuples orientaux et slaves qu'inversement le peuple grec n'a lui-même été influencé, quant à ses manifestations musicales, par les années de domination qu'il a subies ». L'argument racial est sollicité pour expliquer cette souveraineté : «Le compositeur inconnu de la tradition populaire continue l'héritage antique, grand et glorieux, de la musique grecque, et il garde sa chandelle allumée pour offrir sa lumière toujours vive, à travers les siècles, au jeune musicien grec et à la civilisation grecque moderne $»^{138}$. Quant à la tradition européenne, elle est appelée à étayer ce rôle hégémonique ; dans un article de 1922 paru dans Moussiki Épithéorissis, Kalomiris affirme le caractère oriental de la musique grecque, pour laquelle il rêve d'un rôle d'avant-garde parmi les autres musiques orientales, moyennant l'utilisation des innovations occidentales ${ }^{139}$.

Ce radicalisme de Kalomiris l'éloigne des esprits progressistes du mouvement des démoticistes; il n'est pas marginalisé pour autant, car il acquiert entretemps une notoriété qui le rend intouchable. En réalité, c'est l'absence d'une science musicologique digne de ce nom qui lui permet de se maintenir sur son piédestal en spécialiste incontestable, puis en académicien, dont les thèses avaient valeur axiomatique. Depuis cette hauteur, il continue pendant toute sa vie à diffuser ses motos stéréotypes et à revendiquer la gestion de la pensée aussi bien que de l'action musicale néohellénique.

Sous l'emprise du nationalisme musical ainsi installé dans les mœurs, on peut plus facilement interpréter la dépréciation de la modernité musicale en Grèce, malgré son essor dans les pays européens. Une nouvelle génération de compositeurs, dont Skalkottas est sans doute la tête de file, se charge de renverser les idées reçues; en 1930, après un concert où ses œuvres sont présentées au public athénien, Kalomiris rédige une critique assez venimeuse. Il trouve «stérile » la musique de Schoenberg et se demande pourquoi un jeune compositeur comme Skalkottas néglige «le matériel vierge et inexploité de la légende, de la mélodie populaire, de la tradition nationale d'une ethnie dotée de la source artistique primaire la plus variée, la plus glorieuse. Les ères antique, byzantine, médiévale, moderne se présentent au compositeur pour lui offrir les plus précieux éléments artistiques, encore non touchés par la création musicale de notre temps. Aucune des écoles nationales contemporaines ne peut s'épanouir sur des bases aussi sèches et aussi stériles [que le dodécaphonisme] $»^{140}$.

Pour Kalomiris et pour bien d'autres musiciens et penseurs, la recherche esthétique a des limites précises ; le perfectionnement des musiciens et l'éducation du public aussi : «Les œuvres contemporaines, avec leur polytonalité et leur atonalité, sont étranges pour les 
interprètes et le public et demandent une préparation et une éducation spéciales pour être comprises ${ }^{141}$.

\section{L'essor des travaux d'histoire et de musicologie}

100 Au cours de notre présentation, nous avons déjà vu qu'avec leurs écrits, G. Lambelet, P. Pétridis, M. Varvoglis et M. Kalomiris sont les principaux fondateurs de la science musicologique en Grèce. Ils ont tous un point commun non négligeable: formés en Occident, ils ont une bonne connaissance de la musique occidentale et de son évolution historique, ce qui ne les empêche pas de s'occuper en priorité de la musique grecque (démotique ou «byzantine »), dans la perspective d'une transfusion de la première dans la seconde, transfusion dans laquelle chacun d'entre eux s'investit plus ou moins idéologiquement.

101 Leurs travaux ont beaucoup d'influence en Grèce, ce qui est particulièrement visible dans le changement notable que nous repérons dans la critique musicale courante à partir de 1915. Elle est exercée désormais par des personnes qui portent leur attention sur des questions plus substantielles que le simple étalage d'informations ou le ralliement à telle ou telle opinion, c'est-à- dire des questions d'ordre technique et esthétique, voire même des travaux documentés sur l'histoire de la musique en Grèce et en Occident.

La première Histoire de la musique néohellénique paraît en 1919, signée par Th. Synadinos, qui assume la direction des revues musicales Apollon et Moussiki Épithéorissis à partir des années 1910, de Proodos en 1919 et d'Acropolis en 1920 (après la mort de Gavriilidis), tandis qu'il fréquente aussi les pages de critique musicale de Noumas ${ }^{142}$. Grand défenseur de Nazos et de son Conservatoire, il est aussi un grand admirateur de Kalomiris et de l'École Nationale. Animé par un vif souci pédagogique, il traite du problème de l'éducation musicale dans une série de conférences, présentées pour la plupart au Conservatoire. Son Histoire, que nous venons de citer, reste toujours un ouvrage de référence pour son époque, tout comme son étude originale Sommes-nous cultivés en musique ${ }^{143}$, qui est une critique aiguë du public athénien des années 1910-20. En 1922, Synadinos publie une deuxième étude sur la musique grecque. Il s'agit en réalité d'un recueil de cinq conférences sur la chanson démotique, la chanson " pédagogique ", la chanson populaire, la chanson de l'Heptanèse et la chanson « savante ", toutes données à Athènes pendant la période qui précède leur édition ${ }^{144}$.

103 Avec ses écrits, et surtout avec ses deux études, Synadinos est l'instructeur presque exclusif des cercles lettrés sur le sujet de la musique grecque, savante et populaire. À son époque, il est l'historien de la musique le plus connu, qui instaure durablement, avec sa méthodologie conséquente, un certain modèle d'historiographie musicale, qui tient essentiellement aux principes d'une présentation ordonnée. Sa plume est toutefois sélective pour ce qui est de l'enregistrement des données, tandis que son subjectivisme lui permet de se balancer entre l'hagiographie et l'ostracisme. Dans ses écrits, il soutient ouvertement Kalomiris contre les Ioniens, et suit volontiers son chemin pour défendre la notion de la grécité (notamment dans l'introduction de son Histoire).

I. Psaroudas ${ }^{145}$ et S. Spanoudi ${ }^{146}$ sont respectivement les critiques permanents des revues Hestia et Nouvelle Hestia. Le premier est membre de plusieurs conseils de pédagogie musicale, dont celui de la Lyriki Skini, l'Opéra d'Athènes. La seconde évolue plutôt dans le domaine de l'analyse musicale et de l'esthétique. Ancienne élève de Romain Roland à la Sorbonne, elle quitte Paris en 1922 pour s'installer à Athènes; elle devient dès lors la 
critique musicale la plus incontestable de la musique néohellénique. Ses textes figurent dans presque toute la presse de l'époque et témoignent d'une large activité de recherche musicologique, qui va de l'enregistrement des tendances qui font suite à l'École Nationale aux critiques quotidiennes de toute manifestation musicale athénienne, en passant par des questions d'esthétique "byzantine » ou "classique » et d'éducation musicale dans le cadre néohellénique. Sa critique intense contre la «naïveté» des harmonisations populaires de Psachos va de pair avec une attitude favorable à l'égard des jeunes compositeurs de l'École Nationale et leurs successeurs. Son attitude protectrice envers Kalomiris ${ }^{147}$ dote le mouvement de l'École nationale d'un appui théorique non négligeable, surtout en ce qui concerne l'esthétique du traitement des sources populaires; c'est cet appui qui permet d'établir le procédé "orthodoxe» comme le modèle homologué de la création nationale, contre les courants modernes de musique atonale introduits par Mitropoulos et Skalkottas ${ }^{148}$. En ce qui concerne la musique démotique enfin, Spanoudi se compte parmi les acteurs de la campagne pour sa

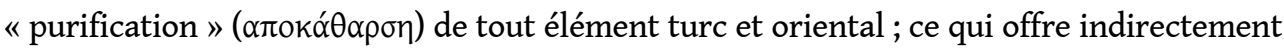
à voir sa propre interprétation du contenu de la grécité ${ }^{149}$.

Deux autres figures féminines se distinguent dans l'histoire de la musicologie grecque : À. Théodoropoulou ${ }^{150}$, musicienne et critique musicale, auteur de nombreux essais et études sur la musique savante grecque et occidentale, et M. Merlier ${ }^{151}$, moins connue pour ses travaux et ses conférences sur la musique savante que pour ceux qui l'imposèrent comme la fondatrice de l'ethnomusicologie en Grèce.

Ce domaine particulier de la recherche occupe Merlier dès son arrivée en Grèce, en 1925. En 1931, elle publie avec le linguiste H. Pernot les Chansons de Roumélie, livre qui dépasse l'esprit de la «collection», qui était celui de Pachtikos ${ }^{152}$, pour constituer le premier travail analytique et systématique sur le folklore grec. C'est à peu près à la même époque que Merlier fonde Les Archives Musicales et Laographiques, un centre qui focalise ses activités sur la tradition musicale grecque provenant des côtes asiatiques de la mer Égée, que la population grecque avait été contrainte de quitter après la guerre de 1922 . Ce terrain de recherche s'élargit avec le temps pour couvrir presque toute la Grèce; il constitue aujourd'hui, avec les Archives de l'Académie d'Athènes, les fonds les plus importants en collections et études sur le folklore grec.

Parmi ses études musicologiques, on distingue plus particulièrement Le premier mode et son plagal ${ }^{153}$ (en français), édité à Paris en 1935, au moment où en Grèce paraissait La laographie musicale en Grèce, un tableau de toutes les régions grecques avec leurs particularités musicales en ce qui concerne les gammes, les rythmes, les danses, etc. ${ }^{154}$. Notons enfin que nous lui devons également une des premières études à caractère purement musicologique concernant la musique de Beethoven, qui a été publiée à Athènes en 1919 et qui est pratiquement introuvable aujourd'hui ${ }^{155}$.

Deux compositeurs, qui partagent les aspirations de l'École Nationale, ont également leur place dans l'historiographie musicologique grecque. Il s'agit de C. Sfakianakis ${ }^{156}$ et de G. Sklavos ${ }^{157}$, dont les articles figurent presque dans tous les dictionnaires et les encyclopédies de l'époque. En 1921-22 Sklavos collabora aussi avec Mousiki Éphiméris, où il présentait systématiquement la création des œuvres des compositeurs de l'École Nationale.

D. Chamoudopoulos prit le relais de S. Spanoudi dans les pages de la Nouvelle Hestia entre 1936 et 1939. Comme celle qui l'avait précédé, il s'occupe de présenter et de critiquer des 
concerts et notamment les nouvelles créations et d'alimenter le débat sur l'École Nationale et son idéologie. Son œuvre la plus importante est L'aube de la musique savante en Grèce et la création de l'École Nationale, écrite probablement juste après la guerre, mais publiée seulement en 1980.

Tous ces auteurs contribuent pour beaucoup à la formation de la culture musicale grecque ; mais ils sont en général très engagés dans cet ensemble de rivalités, offrant un appui notable aux différentes parties. L'impartialité n'est pas la règle dans leur cercle ; non seulement ils alimentent les confrontations, mais souvent ils en déterminent les issues, régulant ainsi les mutations esthétiques et idéologiques et inférant pour beaucoup dans l'établissement des politiques culturelles. L'important toutefois, c'est l'influence qu'ils exercent sur l'opinion publique, contribuant de manière décisive à la formation de représentations sociales solides et durables. Leur formation n'est pas toujours à la hauteur de leur rôle, les mœurs non plus. Dans son grand livre sur Mitropoulos, Trotter est impitoyable: "des provinciaux prétentieux, au service de patrons auxquels ils devaient leur poste et qui exigeaient la promotion de leurs 'affaires' et la louange de leurs compositeurs et interprètes favoris $»^{158}$. En inaugurant en 1926 sa propre colonne critique dans le quotidien Ethnos, colonne qui se maintient pendant trente ans consécutifs, Kalomiris s'impose comme un expert, en réprimandant les critiques «de fortune » qui l'avaient précédé dans ce métier : «Je décidai de me charger de cette tâche difficile, car je crois que c'est mon devoir de contribuer à guider l'opinion publique en ce qui concerne nos affaires musicales. (...) Un terrible bouleversement se produisit dernièrement pour la réception musicale du public à cause de l'invasion barbare de quelques messieurs qui s'autoconsacrèrent "critiques musicaux ». Ces esthètes (ndt. en français dans le texte), jeunes et vieux (...), se sont chargés en tant qu'entrepreneurs d'illuminer les lecteurs de nos journaux. Ils traitent tout noble effort de la plus monstrueuse outrance, ils méconnaissent chaque jeune compositeur ${ }^{159}$.

111 Les citations de ce type sont nombreuses. Si la confrontation entre artistes et critiques est banale, pour la scène musicale néohellénique il est tout aussi vrai que ce terrain « journalistique » était facilement accessible à des soi-disant intellectuels. C'est pourquoi, il se fait très tôt un champ de bataille pour les rivalités personnelles et un tapis rouge pour les ambitions particulières. L'information du public s'en trouve par contre taraudée ; plus grave encore, son éducation musicale se fait ainsi miner. Pourtant, la critique musicale émane de l'élite lettrée de l'époque, c'est-à-dire d'une catégorie sociale assez puissante et suffisamment consciente de son pouvoir de gérer les idées et les politiques, dont le conservatisme joue un rôle très important dans les grandes « questions » comme l'« affaire musicale » et l'enjeu de l'École nationale.

112 Le dernier des champs de controverse pour la période qui nous occupe se forme au sujet de la présence d'éléments orientaux dans la musique populaire urbaine, qui donne lieu à une campagne d'» épuration ${ }^{160}$. La critique musicale épaule bien sûr les conservateurs dans cette cause, mais les limites idéologiques sont déplacées ; les compositeurs de l'École nationale défendent les éléments orientaux et particulièrement l'amané qui se trouve au centre du débat. Kalomiris lui-même suit Palamas dans ses positions en la matière ${ }^{161}$, mais son parti pris ne suffit pas pour ébranler le fort conservateur ; quelques années plus tard, ses préceptes incitent la dictature de Métaxas à instaurer une très originale censure des styles. On doit voir dans cette rupture d'alliances anciennes, comme celle des conservateurs et de l'École nationale, un symptôme de la fin d'une époque d'introversion pour la littérature musicale. La période qui suit apporte des changements notables, 
toujours dans un tourbillon dramatique d'évolutions historiques. La personnalité qui révolutionne la critique musicale après la guerre est Minos Dounias, musicologue formé en Allemagne qui introduit de nouvelles mœurs dans le domaine avec sa distanciation et son attachement aux valeurs esthétiques ${ }^{162}$.

\section{Le paysage musicologique de l'après-guerre : le règne des ethnomusicologues}

Il est bien connu que la Seconde guerre mondiale est suivie en Grèce d'une guerre civile, qui dure jusqu'à la fin des années 1940. À la sortie de ce tunnel, le paysage musicologique présente deux aspects notables. Le premier est que les ethnomusicologues (on doit dire plutôt les laographes musicaux, car leur méthodologie reste toujours très dépendante de celle de la laographie), se démarquent de plus en plus des musicologues. D'abord parce que la science de la laographie gagne du terrain, car la recherche de la grécité est à l'ordre du jour après les grands tumultes socio-politiques, dont l'écho se ressentira jusqu'aux années 1980. Puis parce que les compositeurs grecs de l'après-guerre, se rattachant pour la plupart aux grands courants européens, se désintéressent presque complètement de la tradition populaire, laissant le terrain libre pour de nouvelles approches. Le second aspect à souligner est la forte baisse d'activité dans le domaine de la presse périodique et de l'édition musicale entre 1955 et 1975 (notons que le pays fut sous la domination de la junte entre 1967 et 1974).

114 Il n'est pas exagéré de dire que pendant toutes ces années et jusqu'à très récemment, l'ethnomusicologie régnait dans les études musicales grecques. La liste des ethnomusicologues est trop longue pour qu'ils soient tous énumérés ici. Parmi ceux, peu nombreux, qui continuent à s'occuper de la musique savante, la personnalité la plus intéressante est sûrement $\mathrm{F}$. Anoyannakis, qui collabore avec les quotidiens grecs les plus importants, Avgi et Apogevmatini (1945-50), Ethnos (1955-70), Athens News (1970-75) et Épikéra (de 1975 jusqu'aux années 1980). Il traduit en grec l'Histoire de la musique de Karl Nef, qui sert toujours de manuel dans tous les établissements musicaux ; il annexe à cette traduction une brève " Histoire de la musique grecque ", qui couvre la période jusqu'en 1958, date de la parution du livre. Ami très proche de M. Kalomiris, il publie également le catalogue complet de ses œuvres en 1964. Mais son activité la plus importante se situe dans le domaine de la recherche sur les instruments de musique populaires, dont il publie un catalogue complet avec des considérations organologiques en 1976 (éd. en anglais en 1979) ${ }^{163}$. Collectionneur passionné, il a fait don à l'État grec d'un ensemble d'environ 500 instruments, dans le but de créer un musée, que l'on peut visiter aujourd'hui dans le quartier de Plaka, à Athènes.

115 Dans le premier abrégé de l'histoire de la création musicale savante en Grèce de Anoyannakis, on peut trouver les résidus de toutes les caractéristiques " génétiques » du monde musical grec que nous avons énumérés plus haut. Le paysage musical néohellénique y est décrit à travers les personnalités qui y jouent un rôle important, dont la présentation est inégale et parée des clichés les plus typiques, p. ex. en ce qui concerne les influences italiennes dans l'œuvre de Mantzaros qui n'aurait pas la volonté de "cultiver l'idée de création de musique nationale »"164. L'absence des sources (partitions, analyses d'œuvres, présentations détaillées des compositeurs et des courants esthétiques, etc.) qui restreint sa documentation est déterminante pour le compte-rendu final de l'histoire de la musique néohellénique. À cette lacune s'en ajoute une sur l'arrière-fond historique et le contexte social, absents du tableau, condamnant ainsi les appréciations des personnes et des œuvres à rester suspendus dans une dimension virtuelle, qui les 
prive de leur poids effectif. Il est certain que la musicologie grecque a beaucoup de chemin à faire pour restaurer la carte du paysage musical grec; l'essor récent de la musicologie, à la suite de l'institution de son enseignement universitaire à la fin des années 1980, promet sans doute un renouveau de ce domaine ${ }^{165}$.

Si l'on passe en revue les œuvres des compositeurs grecs des deux derniers siècles, nous constatons que tous les courants musicaux du monde occidental y sont représentés souvent avec un certain retard, certes, mais avec une ponctualité qui étonne, quant on considère les lacunes dans le système grec d'enseignement musical. Du classicisme à la musique électronique, les compositeurs grecs ont su exploiter leur expérience auprès de maitres qu'ils sont généralement allés chercher à l'étranger. Ils n'ont pas pu toutefois fonder en Grèce de véritables écoles de style, à l'exception de l'École Nationale. Quant à cette dernière, elle rassemble stylistiquement les tendances les plus diverses, partant du romantisme et arrivant jusqu'à l'impressionnisme et au néoclassicisme.

Qu'en est-il des textes musicologiques qui devraient refléter ou critiquer ces tendances? On n'en possède que très peu, essentiellement ceux des compositeurs eux-mêmes. Le niveau d'éducation, non seulement en musicologie, mais également en musique, n'était pas assez élevé pour permettre l'essor d'une telle activité; hormis quelques rares exceptions, les critiques et les musicologues grecs les plus importants ont été formés à l'étranger.

118 Mais plus que le problème de l'éducation, la question qui condamne la littérature musicale grecque à une longue stagnation est visiblement celle de la recherche obsessionnelle d'une identité musicale nationale, que celle-ci s'exprime par les querelles autour de la musique «byzantine » ou par la monomanie de la recherche dans le domaine de la musique démotique. Limité à un schéma de confrontation quasiment personnelle, ce type de débat dure depuis des décennies, donnant naissance à une littérature à caractère idéologique plutôt que critique, toujours en retard par rapport à la création musicale contemporaine, qui s'efforce de suivre les rythmes européens.

Il est vrai que cette image de la musique néohellénique est justifiée par le contexte historique et politique de la formation de la Grèce moderne ; le fait qu'elle soit toujours reflétée dans la réalité actuelle est très probablement le signe d'un besoin urgent de prise de conscience.

\section{NOTES}

1. Les deux manuels principaux consacrés à l'histoire de la musique savante grecque sont ceux

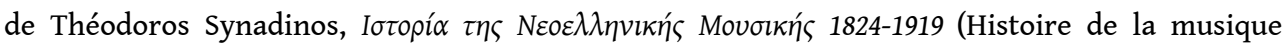

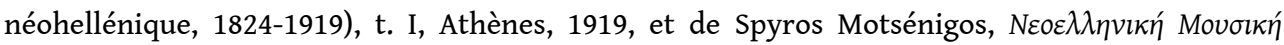
(Musique néohellénique), Athènes, 1958. Un autre manuel, présenté sous forme d'annexe dans la traduction de l'Histoire de la musique de Karl Nef est publié par Fivos Anoyannakis: «H

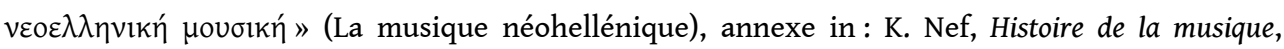

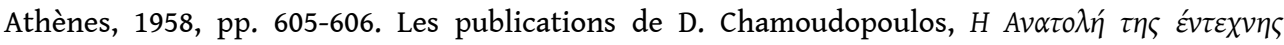

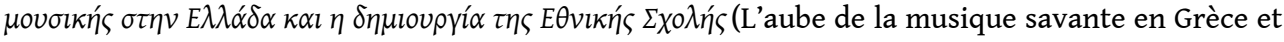




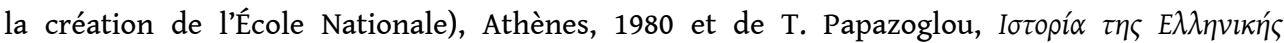

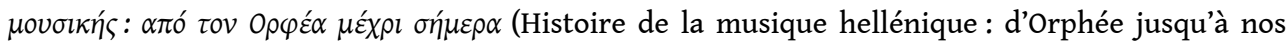
jours), Athènes, s.d., se présentent plutôt comme des abrégés d'histoire de la musique grecque. Récemment la musicologue Kéti Romanou a publié un nouveau manuel d'histoire de la musique, comprenant pour la première fois des fragments d'œuvres suivis d'une courte analyse. $\mathrm{Cf}$. $\mathrm{K}$.

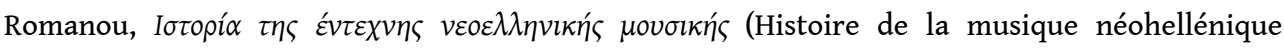

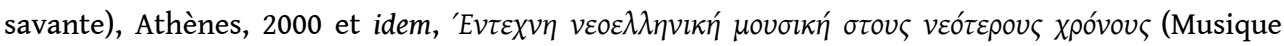
néohellénique savante dans l'ère contemporaine), Athènes, 2006.

2. À titre d'exemple nous mentionnons les articles de G. Léotsakos, "Greece, III: Art music since 1770", in: The New Grove Dictionary of Music and Musicians, 10, Londres, 2001, p. 349-353 et d'Olymbia Frangou-Psychopédis, "Griechenland. B. Neugriechische Kunstmusik », in : Die Musik in Geschichte und Gegenwart, vol. 3, 1995, pp. 1675-1687.

3. La question de la « continuité historique » de la culture grecque depuis l'Antiquité, en passant par Byzance et la période de l'Empire ottoman a été introduite depuis 1850 par l'historien $\mathrm{K}$.

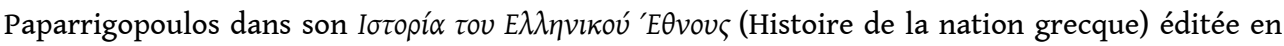
cinq grands volumes, entre 1860 et 1874 , et remaniée pour une deuxième édition entre 1885 et 1888. Très vite cette conception de l'histoire grecque a été mise au service de la Grande Idée, un concept idéologique selon lequel la Grèce « ressuscitée » devait réunir en elle tous les territoires autrefois occupés par les Byzantins, y compris l'Asie Mineure et Constantinople. Son impact sur les consciences était énorme, et il est particulièrement visible tant dans le domaine de la littérature, que dans celui des recherches ethnologiques. Cf. K. Th. Dimaras (éd.),

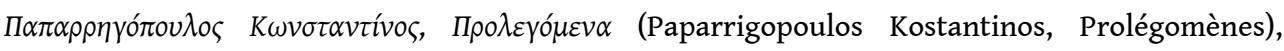
Athènes, 1970, pp. 70-93.

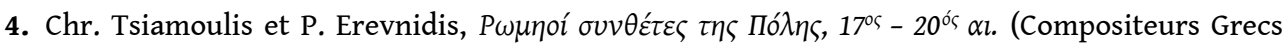
d'Istanbul, XVII $-\mathrm{XX}^{\mathrm{e}} \mathrm{s}$.), Athènes, 1998.

5. Citons à titre d'exemple, dans le journal Phimi du 10/01/1840, la rubrique qui rend compte d'un spectacle d'opéra, se limitant simplement à évoquer le succès qu'il avait eu auprès du public athénien.

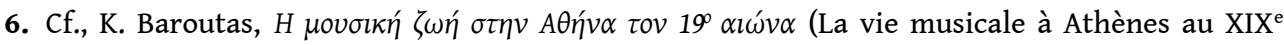
siècle), Athènes, 1992 , p. 75 , note 1.

7. Le mot mélodrame ( $\mu \varepsilon \lambda o ́ \delta \rho \alpha \mu \alpha)$ est utilisé tout au long du XIX ${ }^{\mathrm{e}}$ siècle tant pour des spectacles du mélodrame que pour ceux de l'opéra.

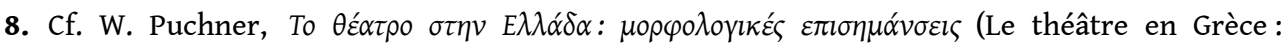
indications morphologiques), Athènes, 1992, pp. 337-338.

9. K. Baroutas, op. cit., p. 15. 10 Th. Synadinos, Histoire de la musique néohellénique, op. cit., pp. 105-106.

10. Th. Synadinos, Histoire de la musique néohellénique, op. cit., pp. 105-106.

11. E. About, La Grèce contemporaine, [Document électronique] Num. BNF de l'éd. de, Paris : INALF, 1961, Paris, 1997, pp. 422-423.

12. K. Baroutas, op. cit., p. 19.

13. K. Baroutas, op. cit., p. 17 et note 17.

14. Ibidem.

15. Le témoignage d'Edmond About est caractéristique : " Athènes, il y a vingt-cinq ans, n'était qu'un village albanais ». Cf. E. About, op. cit. p. 46, voir aussi Y. Tsiomis, « Athènes 1833 : la guerre pour la capitale de l'État-Nation », Études Balkaniques, 12 (2005), pp. 173-176.

16. Ibid., p. 22 et note 29 , p. 75.

17. La création de l'Opéra Hellénique en Grèce s'effectue en trois tentatives. La première, connue comme le Premier Opéra Hellénique a lieu en 1888 à l'initiative de Napoléon Lambelet (frère aîné de Georges). Le Second Opéra Hellénique est créé en 1890 par le producteur I. Karagiannis et le 
Troisième Opéra Hellénique en 1900, par D. Lavrangas et L. Spinellis. Jusqu'à la retraite de Lavrangas en 1935, l'Opéra hellénique avait présenté au public grec 13 opéras grecs et 38 étrangers, pour la plupart italiens. Cf. G. Léotsakos, «H ó $\varepsilon \varepsilon \rho \alpha \sigma \tau \eta \mathrm{E} \lambda \lambda \alpha \alpha \delta \alpha$ » (L'opéra en Grèce), in : Kathimérini-Epta

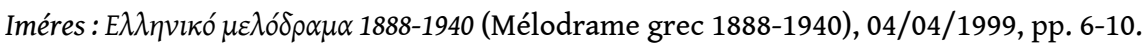

18. K. Baroutas, op. cit., p. 27 et note 51, p. 76. Voir aussi D. Yannou, « The Idea of National Music in Greece ", in Music and Lifeworld-Otherness and Transgression in the Culture of the 20th Century. In memoriam Fernando Lopes-Graça (1906-1994), Congrès retenu à Cascais (Portugal), le 14-17 décembre 1996. Texte inédit, disponible sur le site personnel de Dimitris Yannou : http://www.yannou.gr/ paper1/paper1.htm(consulté en novembre 2006), p. 4 et notes 18 et 19.

19. Th. Synadinos (1880-1959) n'est pas musicien, mais journaliste (il a été collaborateur de plusieurs revues et journaux, ainsi que directeur du quotidien Acropolis) et auteur de pièces de théâtre. Il a été directeur de l'École dramatique du Théâtre National, ainsi que de l'Opéra d'Athènes ( $\left.\Lambda \nu \rho \kappa \eta^{\prime} \Sigma \kappa \eta v \eta^{\prime}\right)$.

20. Th. Synadinos, op. cit., p. 86, pp. 211-212.

21. Ibid., p. $1 \theta$.

22. K. Baroutas, op. cit., pp. 37-38.

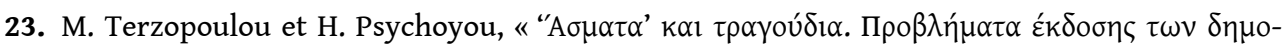

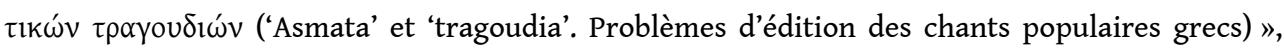
Ethnologhia, 1, 1992, p. 164.

24. On entend ici la musique religieuse de l'église orthodoxe grecque (à distinguer de celle de l'orthodoxie slave), musique vocale caractérisée par des monodies accompagnées par des pédales; remontant au VIe siècle, elle a su préserver ses caractéristiques originales au fil des siècles grâce au conservatisme des milieux ecclésiastique et monacal.

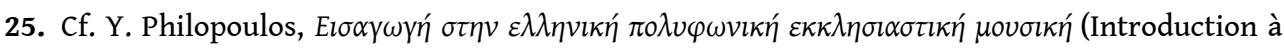

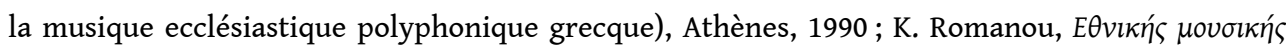

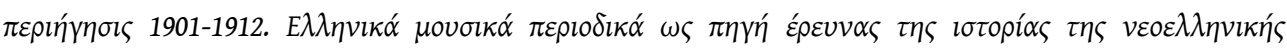

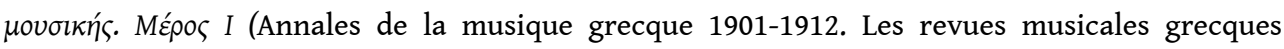
comme source de recherche pour l'histoire de la musique néohellénique. Ière partie), Athènes, 1996, pp. 235- 249.

26. Cf. Y. Philopoulos, op. cit., pp. 26-40.

27. Voir infra.

28. Chantre, journaliste et poète vivement concerné par les débats sur la musique byzantine.

29. Pour plus d'informations, cf. Y. Philopoulos, op. cit.

30. A. Pétsalis est un personnage très représentatif de la société athénienne des dernières décennies du XIXe s. Membre de la «jeunesse dorée " d'Athènes d'alors, il jouissait d'un très grand crédit auprès du compositeur D. Lavrangas, ce qui est significatif pour la notoriété de ses articles et de ses critiques. Cf. D. Chamoudopoulos, op. cit., pp. 95-96.

31. Avocat de profession, ce mélomane averti était également un très bon chantre, ce qui explique son attachement à la préservation de la tradition byzantine. Il a enseigné la musique

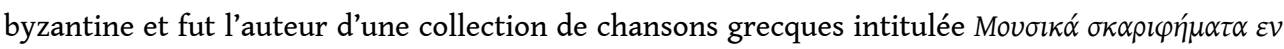

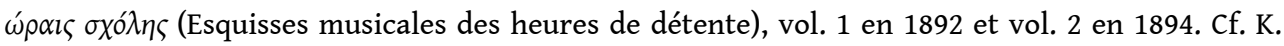
Romanou, op. cit., p. 23, note 34.

32. K. Baroutas, op. cit., p. 26.

33. Sur la personnalité de G. Nazos et la polémique autour du Conservatoire d'Athènes, voir infra. 34. Kostis Palamas (1859-1943) est le plus grand poète de sa génération et le principal représentant de la "Nouvelle école d'Athènes ", cf. C. Th. Dimaras, Histoire de la littérature néohellénique, Institut Français d'Athènes, Athènes 1965, pp. 377-437. Dans sa poésie sont recensés de forts rapports à la tradition poétique populaire. Grâce à son œuvre imposante, il était l'adhérent le plus respectueux des cercles démoticistes. 
35. Cf. K. Baroutas, op. cit., p. 81, et note 128.

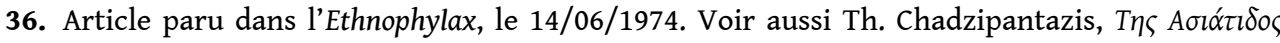
$\mu o v ́ \sigma \eta \varsigma \varepsilon \rho \alpha \sigma \tau \alpha i ́ . .$. (Amoureux de la muse asiatique...), Athènes 1986, pp. 33-34.

37. Il s'agit d'une habitude hebdomadaire instituée par la royauté pour la distraction de ses sujets qui y avaient libre accès. C'est Edmond About qui en décrit l'image pittoresque dans La Grèce contemporaine, op. cit., p. 415.

38. Cf. Th. Chadzipantazis, op. cit., pp. 37-38.

39. Le Conservatoire d'Athènes est engendré au sein de l'Association Dramatique et Musicale, créée en 1871. Il s'autonomise comme institution deux ans plus tard, mais il connaît son vrai essor à partir de 1891, après la reforme de Nazos et avec le soutien financier de l'État.

40. Compositeur natif de Corfou, le frère aîné de Georges Lambelet qui nous occupera plus loin.

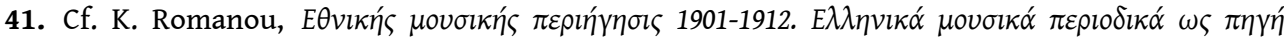

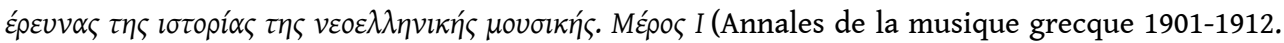
Les revues musicales grecques comme source de recherche pour l'histoire de la musique néohellénique. Ière partie), Athènes, 1996, p. xi.

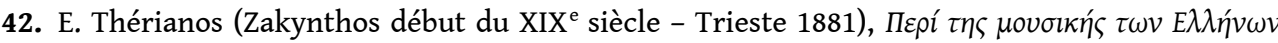
$\kappa \alpha l \imath \delta i ́ \omega \varsigma \tau \eta \varsigma \varepsilon \kappa \kappa \lambda \eta \sigma l \alpha \sigma \tau \imath \kappa \eta \zeta \varsigma$ (Sur la musique des Grecs et notamment la musique ecclésiastique), (première éd. Trieste, 1875), Athènes, 1975, voir aussi D. Yannou, op. cit., pp. 2-3.

43. E. Thérianos, ibid., pp. 54-55.

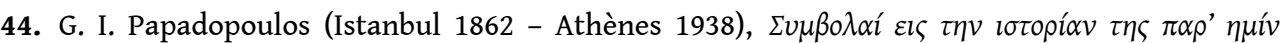

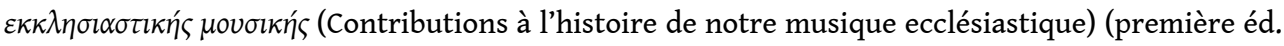
1890), Athènes, 1977.

45. Ibid., p. 286.

46. G. I. Papadopoulos, op. cit., p. 34, 286, 288.

47. Ibid., pp. 509-515.

48. À titre d'exemple nous pouvons citer les illustres études de Konstantinos Protopsaltis,

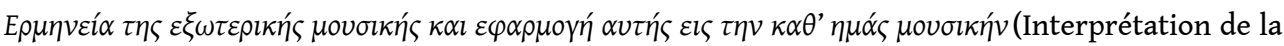
musique séculière et son application à la musique selon nous), Istanbul, 1843, et de Panagiotis

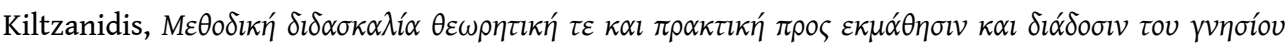

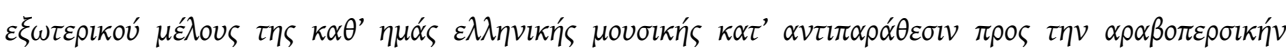
(Enseignement méthodique, théorique et pratique, pour l'apprentissage et la diffusion de l'authentique chant séculier de musique hellénique selon nous, en opposition avec la musique arabo-persane), Istanbul, 1881.

49. Nikolaos Politis (1852-1921), philologue formé en Allemagne, d'où il transplante en Grèce la tradition herderienne, est un des partisans de la théorie de la continuité culturelle et se met en tête de la réaction contre Fallmerayer qui l'avait fortement contestée. Le terme laografia lui appartient; il le créa en 1884 pour signifier l'ethnologie. Ses publications sont nombreuses à partir de 1884 ; en 1908 il lança l'édition périodique de Laografia. Voir aussi M. Grodent, Le bandit, le prophète et le mécréant. La poésie et la chanson dans l'histoire de la Grèce moderne, Paris, 1989, p. 21

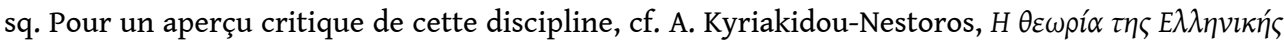
$\Lambda \alpha о \gamma \rho \alpha \varphi i ́ \alpha \varsigma$ (La théorie de l'Ethnographie hellénique), Athènes, 1978.

50. E. Hobsbawm, «Introduction : Inventing Traditions », in : E. Hobsbawm et T. Ranger (éds.), The invention of tradition, Cambridge, 1993.

51. Georges Drossinis (1859-1951), poète et écrivain démoticiste et représentant de la Nouvelle école d'Athènes, dirige avec N. Politis la revue Héstia jusqu'en 1898.

52. Angélos Vlachos (1838-1920) était écrivain, critique et diplomate. Vlachos est issu d'une veille famille noble d'Athènes ; son fils Georges est le fondateur du quotidien Kathimérini.

53. Forme musicale d'expression principalement vocale, très répandue sur le territoire des côtes de l'Asie Mineure. Voir S. Baud-Bovy, Essai sur la chanson populaire grecque, Nauplie, 1983, p. 47. 
54. Commenté par Th. Chadzipantazis, op. cit., p. 39-41.

55. Noumas a marqué l'histoire des lettres néohelléniques car il était l'organe des démoticistes, les défenseurs de l'usage officiel de la langue populaire contre l'utilisation de la katharévoussa, la langue archaïsante que les conservateurs avaient imposée dans la documentation officielle et dans l'enseignement ; le débat, on le devine, allait beaucoup plus loin que la question linguistique, concernant la place du populaire dans la culture néohellénique, hantée par la gloire

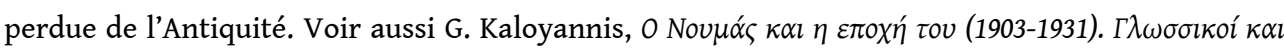

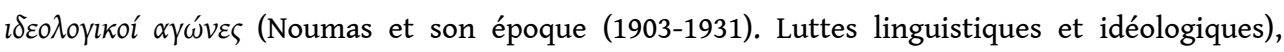
Athènes, 1984.

56. G. Léotsakos affirme que jusqu'en 1868 le gouvernement grec dépense la somme démesurée d'un million de drachmes, ce qui représente un grand pourcentage dans son budget global, pour l'invitation de compagnies théâtrales, afin de distraire les étrangers installés à Athènes. Cf. G.

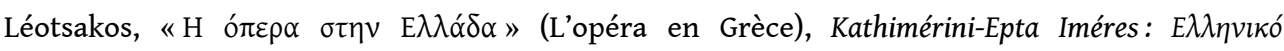
$\mu \varepsilon \lambda o ́ \delta \rho \alpha \mu \alpha$ 1888- 1940 (Mélodrame [opéra] grec 1888-1940), 04/04/1999, p. 7.

57. Au début du XX ${ }^{\mathrm{e}}$ siècle, Athènes dispose de deux Conservatoires (le Conservatoire d'Athènes et le Conservatoire Lottner, créé en 1899 par la pianiste Lina von Lottner [1852-1934]), le Pirée un (le Conservatoire de l'Association du Pirée) et à partir de 1914 Thessalonique dispose de son propre conservatoire, le seul relevant de l'État.

58. Cf. supra note 17.

59. Cf. A. Kostios, «A A

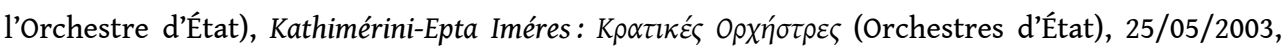
pp. 3-5.

60. Georges Lambelet (1875-1945) se forme en Italie; son œuvre musicale et son activité d'écrivain préparent essentiellement le terrain pour la constitution de l'École Nationale grecque.

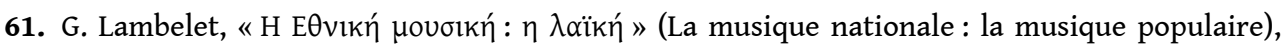

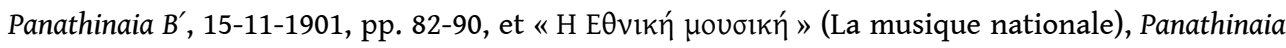

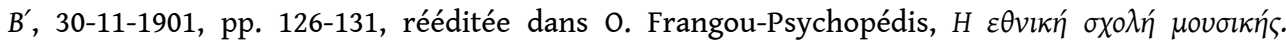

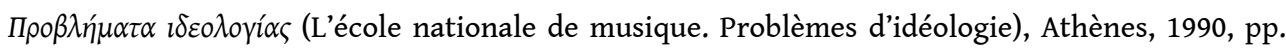
217-240.

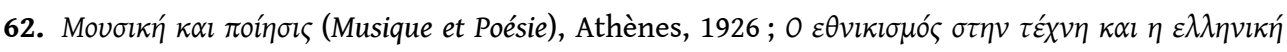

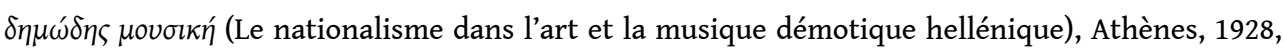
et La musique populaire grecque, 60 chants populaires harmonisés, avec une étude critique (bilingue grec et français), Athènes, 1933-34.

63. Comme critique musical, il travailla dans bon nombre de périodiques, comme Moussiki Ephiméris, Panathinéa, Kritiki, Mousika Chronika, I Kéri, Néa Héstia.

64. Le conflit entre démoticistes (partisans de la langue populaire parlée) et puristes (défenseurs d'un grec moderne "épuré des haillons de l'esclavage ", c'est-à-dire archaïsant) pendant les deux premières décennies du XXe siècle dépasse largement le strict choix linguistique et s'associe à des controverses idéologiques, politiques et sociales d'une envergure très importante. De nouvelles forces sociales, porteuses d'une demande généralisée d'un rétablissement de la société grecque et d'une réforme progressiste, se sont exprimées à travers le mouvement du démoticisme, mais finissent par des choix politiques divers, souvent même contradictoires, allant du socialisme au nationalisme. Les compositeurs rassemblés autour de l'École Nationale, tous d'esprit démoticiste, n'échappent pas à ce sort.

65. Dionyssios Solomos (Zante 1798 - Corfou 1857) est le premier grand poète grec. De 1808 à 1818 il s'installe en Italie pour étudier la philologie latine et italienne. Après son retour en Grèce, il abandonne l'italien pour adopter dans ses écrits le grec et notamment la langue populaire, ce qui provoque la réaction des conservateurs. Inspiré par le chant démotique et la lutte pour la Révolution, il écrit ses plus grandes pages dans un style romantique original quant à la langue, la 
sonorité et la métrique utilisées. Les deux premières strophes de son Hymne à la liberté, un poème de 158 quatrains inspiré par la guerre d'Indépendance, avec une musique de N. Mantzaros sont officiellement choisies comme hymne national grec en juillet 1865, à la suite d'un décret royal. Le Roi Georges I en avait écouté une version pour orchestre philharmonique l'année précédente, lors des fêtes organisées à Corfou pour l'annexion des îles ioniennes à la Grèce. La première version, éditée à Londres en 1873, prévoyait un chœur d'hommes avec accompagnement de piano. La poésie de Solomos influence toutes les générations de poètes grecs du XIXe siècle et reste une référence chère pour tout le $\mathrm{XX}^{\mathrm{e}}$.

66. Andréas Kalvos (1792-1869), est une personnalité très importante, poète, écrivain de pièces de théâtre et d'études critiques. Originaire de Zante, Kalvos était partisan de la tradition grecque classique et de la katharévoussa de Korais.

67. P. Giannopoulos (1870-1910) est connu surtout pour ses essais et écrits critiques. Ses œuvres Ligne hellénique ( $\mathrm{\lambda} \lambda \eta \eta v i \kappa \eta ́ ~ \gamma \rho \alpha \mu \mu \eta ́)$ et Couleur hellénique ( $\mathrm{\lambda \lambda \lambda \eta vi \kappa óv} \chi \rho \omega ́ \mu \alpha)$, ont marqué toute une génération à l'aube du XXe siècle en Grèce. Son style est caractérisé par une écriture agressive et provocante, dans le but de guider les néo-hellènes vers ce qu'il appelle «l'éveil du pays ». Il se suicide à l'âge de 40 ans, en plongeant dans la mer Égée sur un cheval blanc.

68. Spyridon (Filiskos) Samaras (Corfou 1861 ou 1863 - Athènes 1917), contemporain de Lambelet et de Lavrangas, a étudié la musique d'abord à Corfou et ensuite au Conservatoire d'Athènes jusqu'en 1882, pour se rendre ensuite à Paris et aux classes de Delibes au Conservatoire National. Ce contemporain de Verdi et de Puccini fut peut-être le compositeur grec le plus connu en Occident à son époque, car il passa une longue période de sa vie entre Milan et Paris, où il adhéra activement aux cercles musicaux. Sa carrière, c'est en Italie qu'il se la construit : tous ses opéras ont été systématiquement présentés d'abord en Italie et après quelques années seulement en Grèce, où dès son retour il écrit seulement des opérettes.

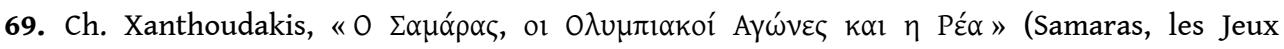

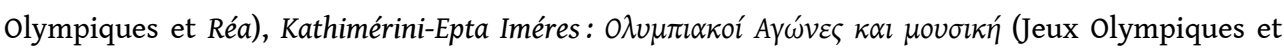
musique), 18/04/2004, p. 4.

70. Iosif Livéralis (Corfou 1820 - Zante 1899) appartient à la génération de Mantzaros.

71. G. Léotsakos pense qu'I. Livéralis est le premier compositeur pour piano en Grèce et le premier représentant d'une "école nationale néohellénique ", puisque son opéra Markos Botsaris et sa suite sous forme de variations pour piano Le Réveil du Klephte, Souvenirs de Chants Populaires de la Grèce Variés pour le Piano, présentent de fortes influences de la tradition populaire grecque ; cf.

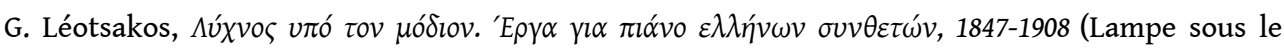
boisseau: œuvres pour piano des compositeurs grecs, 1847-1908), Athènes, 1999, (notice accompagnant l'édition du CD homonyme), pp. 42-43.

72. Voir plus dans G. Léotsakos, ibid., pp. 48-51.

73. Dionyssios Lavrangas (Céphalonie 1860 - Athènes 1941) est le fondateur de l'Opéra Hellénique au début du siècle. Après avoir fait des études musicales à Naples, il devient disciple de Delibes et surtout de Massenet, et fréquente tous les cercles musicaux de Paris avant de s'installer à Athènes en 1894. Il participe avec G. Lambelet à la création de l'École Nationale grecque. À propos de l'Opéra Hellénique, voir supra, note 17.

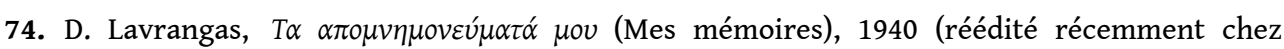
Govostis, Athènes, s.d.), passim. Aux pp. 263-264, l'auteur s'exprime à propos de l'atmosphère villageoise qu'il a voulu créer dans son opéra Le Papillon noir.

75. Pavlos Karrer (Karréris), (Zante 1829-1896) écrit surtout pour l'opéra ; ses œuvres, dont les thèmes sont tirés de l'histoire grecque récente et de la Révolution, ont un succès impressionnant. 76. Genre poétique et musical qui renvoie aux kleftes, les bandits des montagnes grecques qui sont engagés dans la guerre d'Indépendance et à qui la tradition populaire conférait le halo du héros et du martyr. 
77. L'aria a été enregistrée dans plusieurs versions, notamment par des chanteurs de musique urbaine légère au début $\mathrm{du} \mathrm{XX}^{\mathrm{e}}$ siècle, ce qui l'a arraché de son contexte original pour lui conférer une autonomie notable, au point que souvent on a cru (et on croit toujours) qu'il s'agit d'un chant du genre démotique.

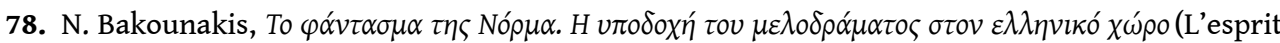
de Norma. La réception du mélodrame dans l'espace grec au XIX ${ }^{\mathrm{e}}$ siècle), Athènes, 1991, p. 101. Une réaction semblable se manifeste aussi en France, juste après le déclenchement de la guerre d'Indépendance pendant laquelle la France se range aux côtés de la Grèce. Le retentissement de ces faits apparaît dans la romance La jeune Grecque (1827) de Dellile, dans la cantate Le départ pour la Grèce (1827) de Roux-Martin, dans le drame lyrique Le dernier jour de Missolonghi (1828) d'Hérold et dans la chanson L'espoir du Grec (1828) de Ropicquet.

79. G. Lambelet, « La musique nationale : la musique populaire », op. cit.

80. Voir infra note 134.

81. L. A. Bourgault-Ducoudray, Trente mélodies populaires de Grèce et d'Orient, Paris-Bruxelles, 1876.

82. G. Lambelet, «La musique nationale : la musique populaire », op. cit.

83. P. Pétridis est un des compositeurs grecs les plus importants du $\mathrm{XX}^{\mathrm{e}}$ siècle. Il a beaucoup travaillé sur les traditions byzantine et populaire, qu'il traite dans son œuvre personnelle de manière polyphonique.

84. Ces articles, publiés entre le 5 mai et le 8 septembre 1916, sont au nombre de huit: deux sur la musique byzantine, un sur la musique démotique, trois sur la musique grecque en général, un sur le compositeur grec M. Varvoglis et un sur les conférences d'Hubert Pernot à la Sorbonne.

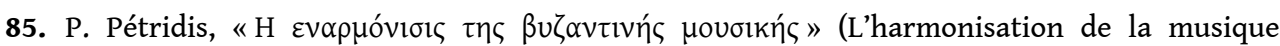
byzantine), Espéria, 6/19 mai 1916, republié in Musicologia, v. 7-8, 1989, pp. 135-137.

86. Les deux premiers, collaborateurs de la revue Noumas, tenaient en effet un rôle protagoniste au sein du mouvement; Riadis y est impliqué assez tièdement, tandis que Mitropoulos suivit toujours le chemin de l'indépendance d'esprit qui fut la sienne.

87. Manolis Kalomiris (Smyrne 1883 - Athènes 1962) est la personnalité qui domine dans l'histoire de la musique néohellénique. Il annonce en 1908 la création de l'École Nationale, dont il est le principal acteur. Après avoir enseigné au Conservatoire d'Athènes (1911-1919) il crée et dirige ses propres Conservatoires : le Conservatoire Hellénique (1919-1926) et le Conservatoire National (1926-1948). Son œuvre de compositeur comprend entre autres cinq opéras, trois symphonies, deux poèmes symphoniques, un concerto pour piano, et plusieurs œuvres de musique de chambre, ainsi que des cycles de mélodies.

88. Pour plus d'informations sur ce sujet, voir K. Romanou, op. cit., pp. 17-29.

89. Konstantinos Psachos (1869-1949) est né à Istanbul où il complète ses études musicales dans la Grande école hiératique. En 1898 il est le fondateur de l'Association Musicale Ecclésiastique de

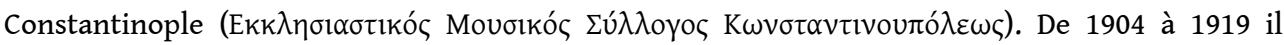
occupe le poste de directeur de l'école byzantine du Conservatoire d'Athènes. Il publie de nombreuses études sur la musique ecclésiastique et le chant démotique. Il invente et dessine un instrument, le Panharmonium, une sorte d'orgue avec des possibilités de modification d'intervalles dépassant le système tempéré; cet instrument fut commandé en Allemagne, mais il

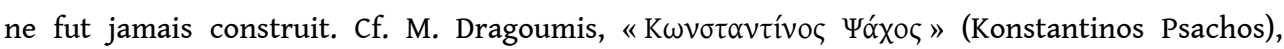

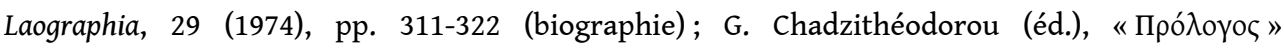

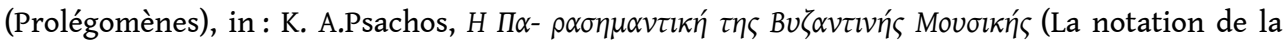

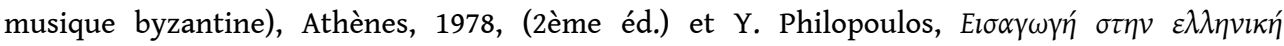

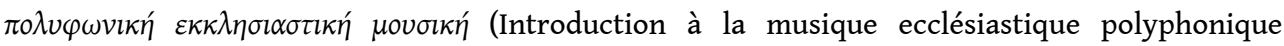
grecque), Athènes, 1990, pp. 145-151 (à propos de son implication dans la « question musicale »).

90. Th. Sakellaridis était un chantre très distingué ; professeur de musique byzantine, il était aussi compositeur de musique religieuse de style byzantin, ainsi que de musique de théâtre qui 
devait accompagner des représentations de dramaturgie antique. Son fils Théophrastos est un des compositeurs les plus distingués de l'opérette grecque.

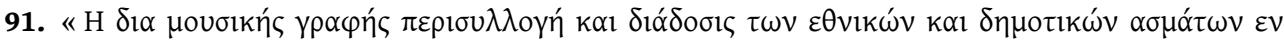

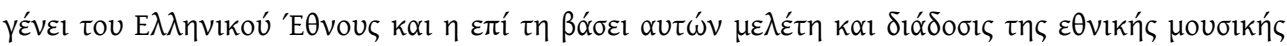

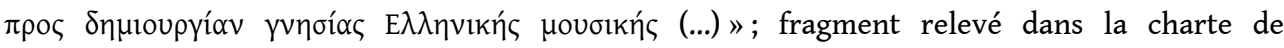
l'Association. Voir K. Romanou, Annales de la musique grecque 1901-1912. Ière partie, op. cit., pp. 189-194.

92. Installé à Istanbul, Georges Pachtikos (1869-1916) avait la réputation d'un compositeur estimable, qui défendait l'authenticité de la musique grecque antique, byzantine et démotique. On lui doit un certain nombre d'études musicologiques sur les chants populaires. Son recueil 260 $\Delta \eta \mu \omega ́ \delta \eta E \lambda \lambda \eta v \imath \kappa \alpha ́$ chants $\alpha ́ \sigma \mu \alpha \tau \alpha$ (260 démotiques grecs), Athènes, 1905, en est le plus notable.

93. Cf. K. Romanou, op. cit., p. 49.

94. Physicien et mathématicien, Stamatiadis était un démoticiste engagé et un bon connaisseur

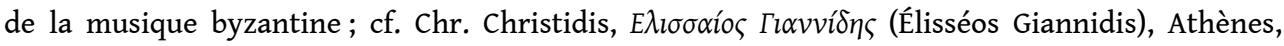
1981.

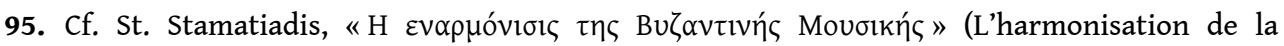
musique byzantine), Ekklissiastiki Alithia, série d'articles édités successivement en 27/11, 4, 25, 31/12 de 1910 et $8,15 / 01 / 1911$.

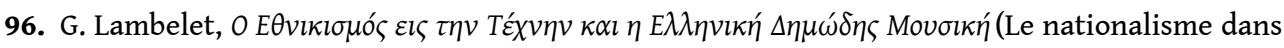
l'art et la musique démotique grecque), Athènes, 1986 (réimpression de la première édition de 1928), pp. 34-37.

97. Cette revue prend le relais de Phorminx (citée plus haut) à partir de 1921, quand K. Psachos se charge de sa direction.

98. En fait, pour le charger de la direction de l'école byzantine du Conservatoire d'Athènes, G. Nazos a fait venir Psachos d'Istanbul, moyennant l'intervention du patriarche Joachim III ; l'«école de Constantinople» était connue pour son conservatisme extrême, auquel les représentants de l'école d'Athènes se sont opposés plus d'une fois.

99. La publication la plus importante de cette collection voit le jour en 1930 sous le titre « 50

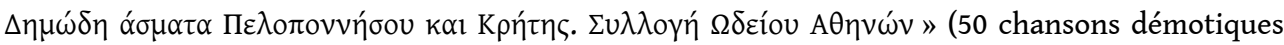
du Péloponnèse et de Crète. Collection du Conservatoire d'Athènes), sous la direction de Nazos G., K. Psachos et A. Marsick, édité chez Sidéris à Athènes en 1930.

100. C'est l'initiative d'A. Tsiknopoulos, avocat, puis chantre et directeur d'une école de musique byzantine; il s'occupe aussi de recenser des chants démotiques, qu'il a fait transcrire selon le système de notation byzantine.

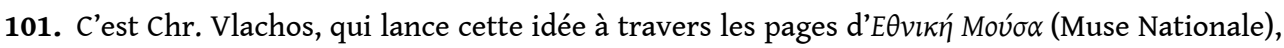
dont il était le rédacteur principal. La revue qui, comme nous l'avons noté plus haut, était l'organe de l'Association Nationale de Musique, émettait une forte critique contre le Conservatoire et contre G. Nazos en personne. Ainsi l'adhésion de Samaras à l'Association en 1907 devient pour les adversaires un casus belli.

102. K. Romanou, op. cit., p. 102, n. 8.

103. Georges Axiotis (1875-1924) a fait ses études musicales en Italie. De 1903 à 1905 il est directeur du conservatoire du Pirée ; il propose une réforme radicale du système de l'éducation musicale (voir son étude intitulée De l'histoire aux faits parue à Athènes au cours des années 1910), à l'occasion de laquelle il adresse des reproches à presque tout le monde musical contemporain.

104. K. Romanou op. cit., vol. I, p. 164, n. 1.

105. Le cas le plus typique de cette tendance est sans doute le chanteur Aramis (Périklis Aravantinos, Ioannina 1854 - Paris 1932), qui donnait des concerts à Athènes et surtout à Paris, où il a aussi enseigné la chanson, dans une petite école de musique privée. Le programme de ses concerts consistait en des interprétations de chansons démotiques arrangées pour voix et piano.

106. K. Romanou, op. cit., p. 169. 


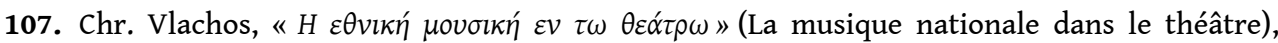
Phorminx, 30/01/1903, commenté dans K. Romanou, op. cit., pp. 165-166.

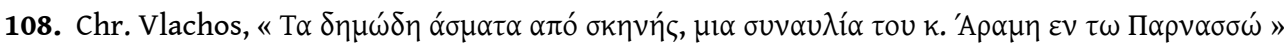
(Les chants démotiques sur scène, un concert de M. Aramis à Parnassos), Phorminx, 15/01/1903, commenté dans K. Romanou, op. cit., p. 170.

109. R. C. Ridenour, op. cit., pp. 69-85, 124-131, 211-213.

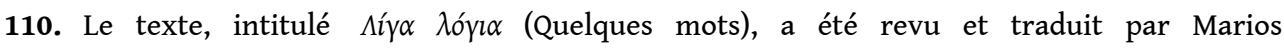
Chryssikopoulos et peut être consulté sous forme électronique sur le site des Archives de Kalomiris, http://www.kalomiris.org.

111. Cf. K. Romanou, op. cit., pp. 211-219.

112. Konstantin Pop, partisan du mouvement des puristes et directeur du quotidien Athinai, avait violemment critiqué le programme ; les démoticistes y étaient surnommés de maliaroi, c'està-dire "poilus ", un adjectif qui marquera l'affaire. Kalomiris y était accusé d'avoir servi la propagande russe.

113. Grigorios Xénopoulos (1867-1951) figure notoire parmi les gens de lettres de son temps, prosateur, écrivain de pièces de théâtre et critique, qui contribue au renouvellement de la littérature et du théâtre néohelléniques au début du XXe siècle.

114. La critique de Xénopoulos a été publiée le 29 juillet de 1908 dans le quotidien Athinai, puis la

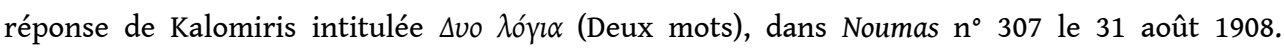
Xénopoulos a répondu par un nouvel article dans le même quotidien le 5 septembre et Kalomiris a réagi immédiatement par un grand article publié dans Noumas no 316 le 2 novembre sous le

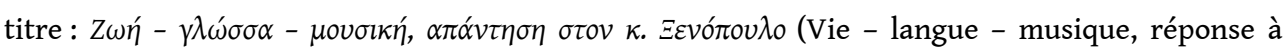
Monsieur Xénopoulos).

115. L'adjectif roméique est synonyme de l'adjectif grec. Il dérive des mots romios(Rum) et romiossini (le peuple grec), et renvoie aux Romains (en grec moderne Romii) de l'époque byzantine et de l'Empire ottoman. Pour plus de détails, voir Maria Madouvalou, «Romain - Romios et

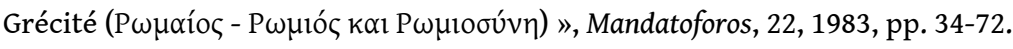

116. Nous rappelons que c'est l'époque des rumeurs préconisant le rapatriement de Samaras pour qu'il se charge de la Direction du Conservatoire; or Kalomiris convoitait ce poste

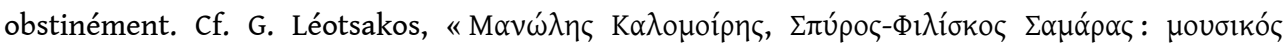
$\delta ı \chi \alpha \sigma \mu o ́ \varsigma ~ \kappa \alpha ı ~ \varepsilon \mu \varphi v ́ \lambda_{1} \circ \varsigma »$ (Manolis Kalomiris, Spyros-Philiskos Samaras : sécession et guerre civile musicale), Ta Néa, Athènes, 20-1-2000.

117. Th. Synadinos, « To $\Omega \delta \varepsilon i ́ o ~ \mu \alpha \varsigma$ » (Notre Conservatoire), Noumas, no 367 (22/11/1909), pp. 4-5. 118. Il s'agit d'une série de lettres ouvertes numérotées, toutes publiées dans Kritiki; G.

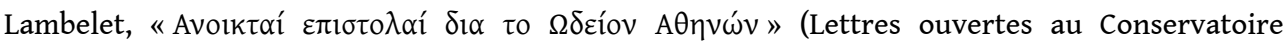

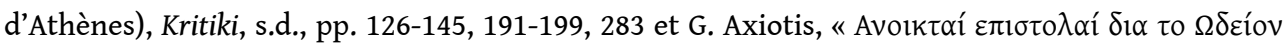

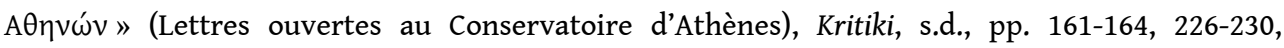
319-327.

119. Le 15 août 1909 un ensemble de jeunes officiers avec le soutien de 5.500 soldats protestent en exigeant des réformes à tous les niveaux de la gestion administrative. L'action de ce mouvement a conduit le parti des libéraux d'Elephthérios Vénizélos à la victoire aux élections de 1910.

120. Th. Synadinos, « Notre Conservatoire ", art. cit.

121. Marios Varvoglis (1885-1967) a suivi des études de musique à la Scuola Cantorum, à Paris, auprès de Vincent d'Indy. En rentrant à Athènes en 1920, il se range aux côtés de M. Kalomiris et soutient la cause de l'École Nationale. Il compose de la musique pour orchestre, de la musique de chambre, des chants et de la musique destinée aux représentations du théâtre antique. Pour Sainte Barbara, son opéra inachevé, ainsi que pour son poème symphonique Le Panygiri, il se laisse fortement influencer par la tradition populaire grecque. 


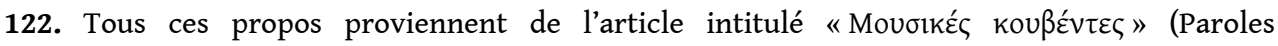
musicales), Noumas, no 372, (27/12/1909).

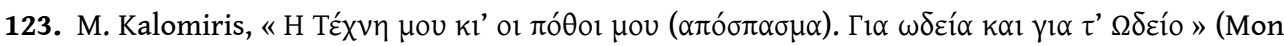
art et mes désirs (fragment). Pour les conservatoires et pour le Conservatoire), Noumas, n. 377, (31/01/1910).

124. M. Kalomiris, "Pour les conservatoires et pour le Conservatoire... », op. cit.

125. Sa démission fait sensation, car elle a pris des proportions politiques et sociales; elle a entraîné celle de neuf autres professeurs, qui l'ont suivi dans la création du Conservatoire Hellénique la même année. Le Conservatoire Hellénique a repris en réalité les infrastructures de l'ancien Conservatoire Lottner. Sept ans plus tard, Kalomiris crée le Conservatoire National, une institution qui représente dès lors pleinement son idéologie. L'historique du conflit est exposé en

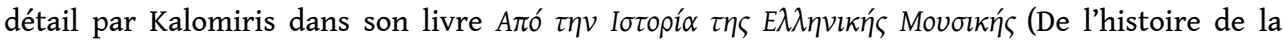
musique hellénique), Athènes, 1919.

126. Kalomiris admet avoir été marqué par la lecture de To $\tau \alpha \xi i \delta \imath \mu \nu v$ (Mon voyage) de Y. Psycharis, le livre-culte du mouvement des démoticistes, qu'il a découvert pendant sa formation

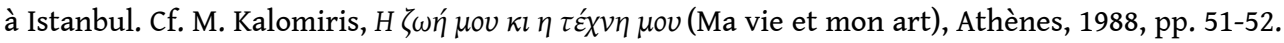
Ce roman publié en 1888 «marquait une étape non seulement linguistique, mais aussi littéraire. Les écrivains qui mettent en pratique les leçons de Psycharis adoptent le démotique, la langue parlée par le peuple ; beaucoup plus expressif, le démotique contribue à l'essor du naturalisme » ; A. Benoit-Dusaysoy et G. Fontaine, (dir.), Histoire de la littérature européenne, Paris, 1992, p. 655.

127. M. Kalomiris, Ma vie et mon art, op. cit., pp. 112-125.

128. Lui-même écrivait dans ses mémoires : «... Mon isolement en Russie avait enflammé en moi le nationalisme et le patriotisme. Par une véritable effusion et un extraordinaire élan je rêvais constamment de la renaissance néohellénique et j'espérais en un Messie qui offrirait à la Grèce ses premières grandes ailes, comme dit Palamas dans un de ses poèmes ", M. Kalomiris, Ma vie et mon art, op. cit., p. 133.

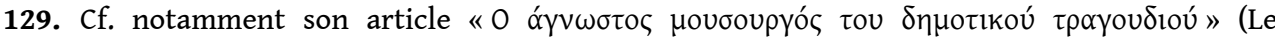

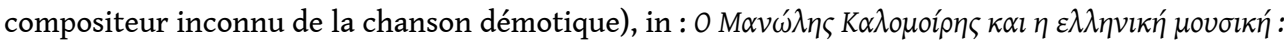

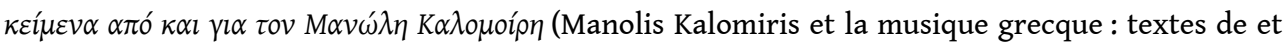
pour Manolis Kalomiris), Festival 'Manolis Kalomiris', Samos, 1997, pp. 13-20. La traduction de ce texte en français est faite par Philippos Tsalachouris et se trouve sur le site des Archives Kalomiris, http://www.kalomiris.org. Ce texte constituait le corps principal de l'allocution du compositeur le jour de sa nomination à l'Académie d'Athènes, le 8 juin 1946. Cf. M. Kalomiris, « $O$

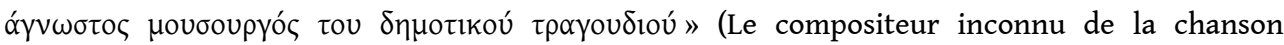
démotique), in : Annales de l'Académie d'Athènes, 21, Athènes, 1946, pp. 274-290.

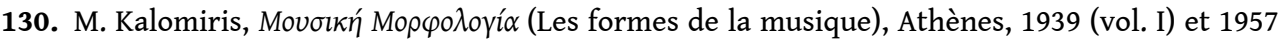
(vol. II).

131. Édité chez Gaïtanos, Athènes, 1933 (vol. I) et 1935 (vol. II). Voir aussi M. Kalomiris, « Пعpí

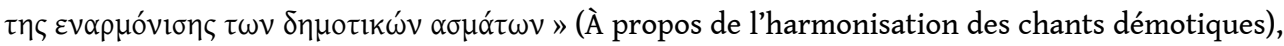
in: Annales de l'Académie d'Athènes, 23, Athènes, 1948, pp. 417-425.

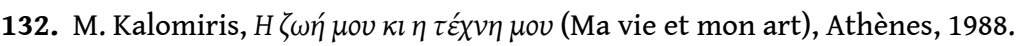

133. "[Les Ioniens] ignorent même des aspects techniques musicaux de base »; M. Kalomiris, Ma vie et mon art, op. cit., p. 137. Voir aussi à ce sujet O. Frangou-Psychopédis, op. cit., pp. 98-106.

134. G. Lambelet, La musique populaire grecque. Chants et danses, Constantinidès (Édition en français), Athènes, 1934, pp. 20-28.

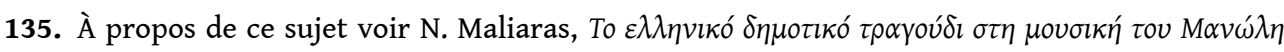

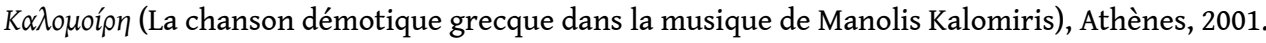

136. Le cas le plus typique de cette tendance est sans doute le chanteur Aramis, voir supra n. 105.

137. G. Lambelet, « La musique nationale », art. cit. 
138. M. Kalomiris, « Le compositeur inconnu... », art. cit., p. 14.

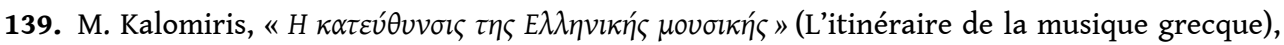
Moussiki Épithéorissis, n. 9, juin 1922.

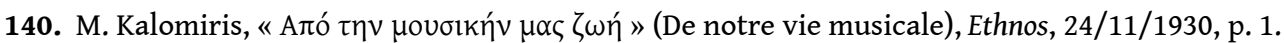

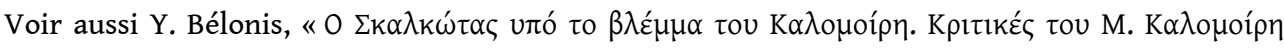

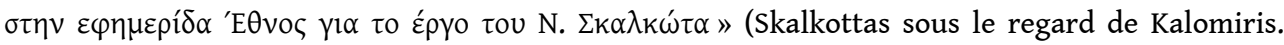
Critiques de M. Kalomiris dans le quotidien Ethnos pour l'œuvre de N. Skalkottas), Polyphonia, 1, 2002, pp. 29-48.

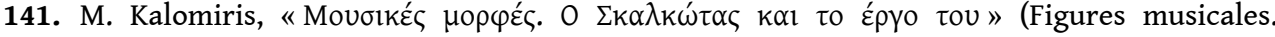
Skalkottas et son œuvre), Ethnos, 4/4/1950, p. 2. Voir aussi Y. Bélonis, «Skalkottas sous le regard de Kalomiris. », op. cit., pp. 29-48.

142. K. Romanou, op. cit., p. 29, n. 42.

143. Sans date, ni nom d'éditeur.

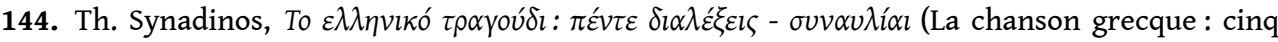
conférences - concerts), Athènes, 1922.

145. Ioannis Psaroudas (1871-1952) étudie la musique près de Massenet, à Paris. Il est l'auteur de nombreux articles à sujet musical, dans Héstia, Élefthéro Vima et Néa.

146. Sophia Ioannidou-Spanoudi (1878-1952) fait des études à Dresde (piano) et à Paris (musicologie). Professeur de piano à Istanbul (1900-1910), après la guerre de 1922 elle est contrainte de se réfugier à Athènes, où elle se consacre à la critique musicale et à la musicologie. 147. C'est Spanoudi qui a initié Kalomiris à l'art de piano, et surtout à l'esthétique de la musique romantique allemande, pendant ses années de formation à Istanbul (1899-1901). Dans ses mémoires, écrites peu avant et pendant la deuxième guerre, le compositeur reconnaît sa dette ;

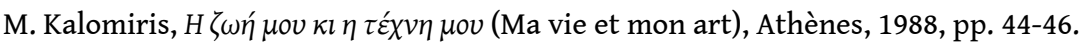

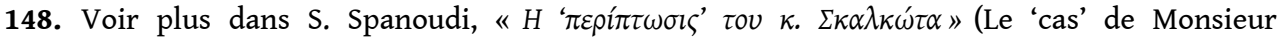

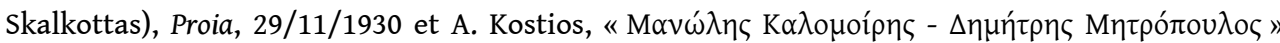

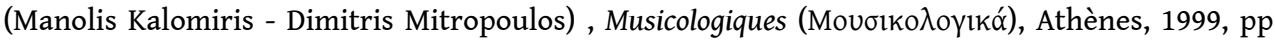
94-98.

149. À propos de la grécité de la musique de Kalomiris, voir O. Frangou-Psychopédis, op. cit., pp 160-162. Pour un résumé détaillé des positions de Spanoudi vis-à-vis de la musique populaire

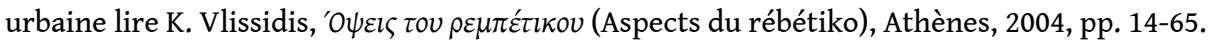

150. Avra Théodoropoulou (1880-1963) étudie le piano au Conservatoire d'Athènes, où elle enseigne à son tour de 1900 à 1919, quant elle part avec Kalomiris pour le suivre dans son Conservatoire Hellénique. Parmi les premières femmes grecques, elle entame une activité d'écrivain considérable (ouvrages de pédagogie musicale, un manuel d'histoire de la musique en deux volumes édité par le Conservatoire Hellénique [1924], traités théoriques sur la musique occidentale et néohellénique).

151. Melpo Logothétis-Merlier (1890-1979) a suivi des études de piano à Dresde et à Vienne. De 1913 à 1919 elle enseigne le piano et l'histoire de la musique aux conservatoires d'Athènes et du Pirée. En 1919 elle se rend à Paris pour étudier la musicologie près de M. Emmanuel et A. Pirro. Son mari Octave Merlier étant nommé directeur de l'Institut Français d'Athènes, elle s'y installe à partir de 1925 pour se consacrer essentiellement à des travaux ethnomusicologiques. En 1930 elle fonde Les Archives Musicales et Laographiques qui ont été par la suite annexées au Centre d'Études Micrasiatiques, créé en 1949.

152. Cf. supra, n. 92.

153. Bibliothèque Musicale du Musée Guimet, II ${ }^{\text {ème }}$ série, t. II, Paris 1935.

154. Ce livre parut également en français la même année 1935, sous le titre Essai d'un tableau du folklore musical grec. 
155. Pour le catalogue complet des écrits de M. Merlier, consulter l'article de M. Dragoumis «H

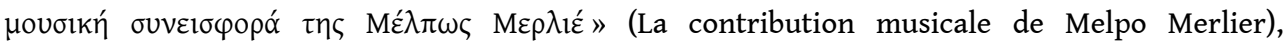
Musicologia, v. 5-6, 1987, pp. 55-62, Deltion Kentrou Mikrassiatikon Spoudon 2, Athènes, 1980 (reéd. in Musicologia 5-6/87, Thessalonique, 1988, pp. 55-62).

156. Konstantinos Sfakianakis (1890-1946) a abandonné ses études de droit à Lausanne pour étudier la musique à Leipzig avec Max Reger et Hugo Riemann. De retour à Athènes en 1922, il a enseigné le piano et la composition au Conservatoire Hellénique de Kalomiris, dont il fut plus tard le directeur.

157. Georges Sklavos (1888-1976) a étudié la musique au Conservatoire d'Athènes, où il enseigne de1913 à 1968. Dans ses compositions, il exploite la musique byzantine avec un support harmonique plutôt romantique.

158. W. R. Trotter, op. cit., p. 56.

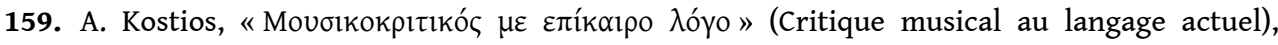

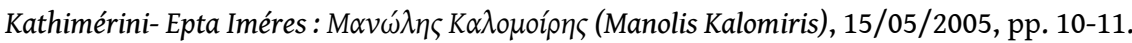

160. Pour plus d'informations sur ce sujet voir Th. Chadzipantazis, Amoureux de la muse asiatique...

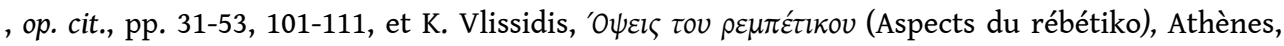
2004, pp. 14-65.

161. Voir les quotidiens Tharros, (article de 29/02/1939) et Ethnos (articles de 8/01/1947, 17/07/1954, 02/11/1954).

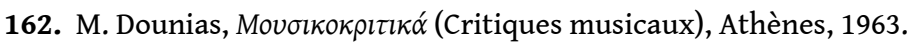

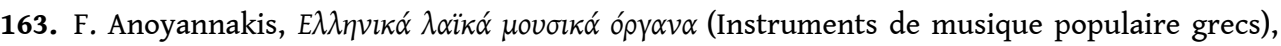
Athènes, 1976.

164. G. Lambelet, «La musique nationale... », réédité dans O. Frangou-Psychopédis, op. cit., p.

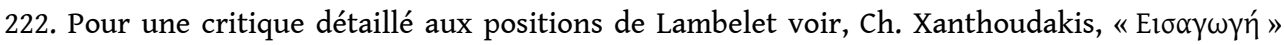

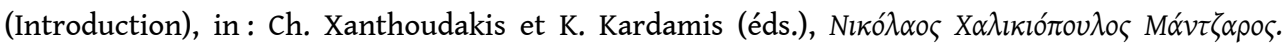

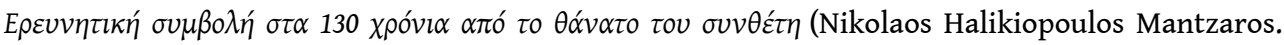
Contribution à la recherche pour les 130 ans de la mort du compositeur), Corfou, 2003, pp. 13-33.

165. Ainsi, la question de l'école ionienne a été radicalement révisée après un certain nombre d'études récentes. À part celle de Ch. Xanthoudakis citée plus haut, G. Léotsakos s'y réfère dans

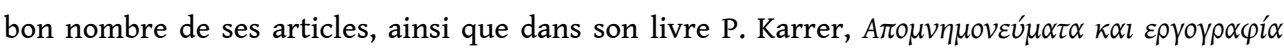
(Pavlos Karrer. Mémoires et œuvre), Athènes, 2003. Une étude complète sur Samaras, du même auteur, se trouve au stade de la publication.

\section{RÉSUMÉS}

L'article met en valeur le rôle essentiel de la littérature musicologique dans le processus de conceptualisation de l'identité nationale dans la musique savante en Grèce. Dans ce cadre, la grécité a été, depuis le XIX et jusqu'au milieu du $\mathrm{XX}^{\mathrm{e}}$ siècle, une valeur artistique évaluative, qui a favorisé l'adoption de stéréotypes encore vivaces.

The article emphasizes the signification of musicological literature in the process of conceptualizing national identity in Greek art music. In this frame, Greecity has been, from $19^{\text {th }} \mathrm{c}$. and until the mid- $20^{\text {th }}$. c., an axiological artistic value which favored the adoption of yet enduring stereotypes. 


\section{AUTEUR}

\section{GEORGES KOKKONIS}

Institut technologique d'Épire, Arta 